\title{
Journal of Chemical \& Engineering Data
}

Msc: je9b00607

The following graphic will be used for the TOC:

Solvent for combined $\mathrm{H}_{2} \mathrm{~S}$ removal and dehydration of natural gas

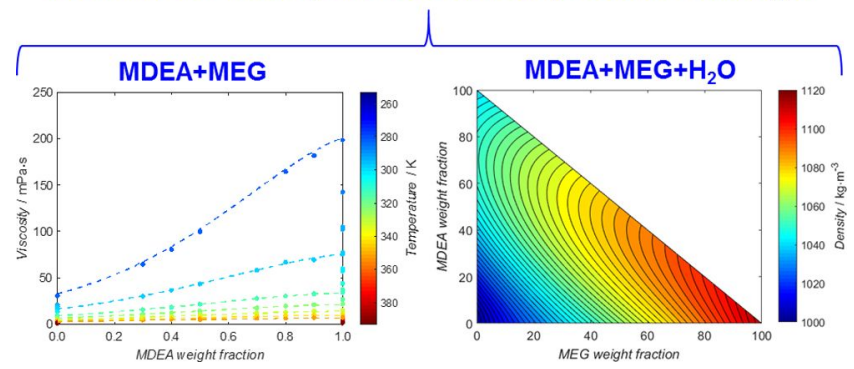




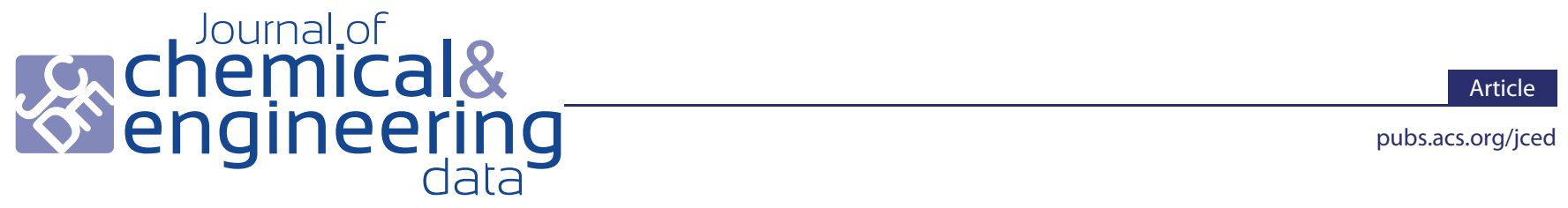

\title{
Density and Viscosity of the Nonaqueous and Aqueous Mixtures of 2Methyldiethanolamine and Monoethylene Glycol at Temperatures from 283.15 to $353.15 \mathrm{~K}$
}

\author{
${ }_{4}$ Eirini Skylogianni, Ricardo R. Wanderley, Sigrid S. Austad, and Hanna K. Knuutila*(0) \\ 5 Department of Chemical Engineering, Norwegian University of Science and Technology, 7034 Trondheim, Norway
}

6

Supporting Information

ABSTRACT: Nonaqueous and aqueous mixtures of methyldiethanolamine and monoethylene glycol form promising absorbents for the combined hydrogen sulfide removal and hydrate control, necessary in natural gas processing. In this direction, the density and viscosity of the binary and ternary systems were measured and modeled in the temperature range of $T=283.15-353.15 \mathrm{~K}$ and at ambient pressure. Excess molar volumes and viscosity deviations from ideality were also calculated. The water content varied from 5 to $50 \mathrm{wt} \%$ and the amine content from 5 to $90 \mathrm{wt} \%$. Both density and viscosity were modeled using nonrandom two-liquid-based models.

Solvent for combined $\mathrm{H}_{2} \mathrm{~S}$ removal and dehydration of natural gas
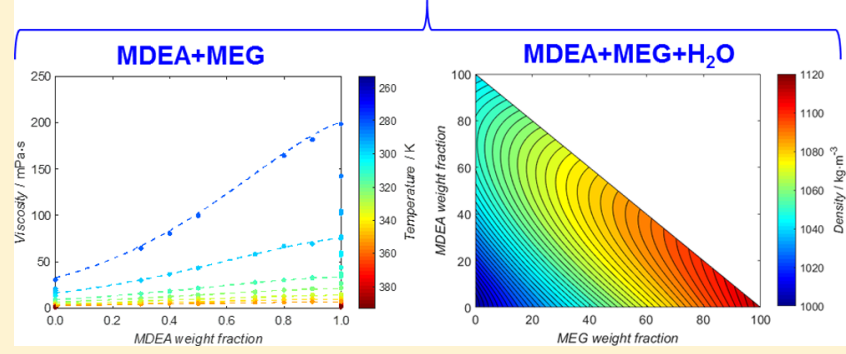

Regarding the density modeling, the average absolute relative deviations (AARDs) were found to be less than $0.4 \%$ for the binary subsystems and equal to $0.3 \%$ for the ternary system. Viscosity modeling results show higher AARD, though always lower than $3.0 \%$ for both binary and ternary solutions.

\section{INTRODUCTION}

21 Acid gas removal with the aid of amines is a common industrial 22 process, for example, in oil refineries and natural gas treatment 23 plants among others. Commercial amines are monoethanol24 amine, diglycolamine, and methyldiethanolamine (MDEA), the 25 latter being most suitable for the selective removal of hydrogen 26 sulfide $\left(\mathrm{H}_{2} \mathrm{~S}\right)$ over carbon dioxide $\left(\mathrm{CO}_{2}\right) .{ }^{1}$ In oil and gas pro27 duction, hydrate control or dehydration is an equally necessary 28 process as gas sweetening. Typically, glycols such as mono29 ethylene glycol (MEG) and triethylene glycol are used, respec30 tively, to prevent hydrate formation during gas transportation 31 and to reach water content specifications. ${ }^{2,3}$ Moreover, the focus 32 of oil and gas companies on subsea operations encourages 33 process intensification concepts, where modules with respect to 34 size, weight, and complexity are developed. ${ }^{4}$ Such a concept is 35 the combined removal of acid gases and water vapors in one step 36 only, first conceived and patented by Hutchinson ${ }^{5}$ and later 37 further developed by McCartney ${ }^{6,7}$ and Chapin. ${ }^{8}$ In this 38 direction, our group investigates the feasibility of the simulta39 neous acid gas removal and hydrate control process with 40 nonaqueous and aqueous MDEA-MEG mixtures.

41 As in every new process analysis, the evaluation of the com42 bined acid gas and water vapor removal by an amine-glycol43 based solvent requires the knowledge of the thermodynamic 44 behavior, reaction kinetics, and physical properties of the 45 system. This study focuses on some of the physical properties of 46 the system, namely, density and viscosity, which play a crucial 47 role in the successful design and operation of a separation 48 process. Nookuea et al. studied the effect of various thermo49 physical properties on the design of an absorber for $\mathrm{CO}_{2}$ capture and concluded that liquid density and viscosity have the most 50 significant impact on the packing height. ${ }^{9}$ Especially for subsea 51 applications, the low temperature experienced in the seabed 52 dramatically changes the solvent viscosity, affecting the overall 53 mass transfer and hydrodynamics of the system. In fact, viscosity 54 specifications related to the pumpability of injected chemicals 55 apply for offshore/subsea operations. Therefore, the objective of 56 this study is to provide experimental measurements and develop 57 auxiliary models for density and viscosity as a tool for assessing 58 the successful employment of the binary MDEA-MEG or the 59 ternary MDEA-MEG- $\mathrm{H}_{2} \mathrm{O}$ systems for natural gas purification. 60

The literature is rich in density and viscosity studies for 61 aqueous MDEA solutions due to their broad applicability in 62 $\mathrm{CO}_{2}$ capture and selective $\mathrm{H}_{2} \mathrm{~S}$ removal. Several authors report 63 densities $^{10-14}$ and viscosities ${ }^{11-19}$ of MDEA- $\mathrm{H}_{2} \mathrm{O}$ mixtures. 64 Moreover, the measurement of the density and viscosity of pure 65 MDEA has been presented as a validation for the experimental 66 method of density and viscosity measurements. ${ }^{20}$ A sufficient 67 amount of data exists also for MEG- $\mathrm{H}_{2} \mathrm{O}$ system densities and 68 viscosities. ${ }^{21-26}$ A comprehensive, though not exhaustive, list is 69 shown in Table 1 . The combination of amines and glycols has 70 also been studied in the literature; ${ }^{27-30}$ however, to the best of 71 our knowledge, no data on the density or the viscosity of the 72 MDEA-MEG or MDEA-MEG- $\mathrm{H}_{2} \mathrm{O}$ mixtures are reported. 73 In addition, although for pure monoethylene glycol and its 74 solutions with water, density and viscosity measurements have 75

Received: June 26, 2019

Accepted: October 25, 2019 
Table 1. Literature Review on the Density and Viscosity Measurements of Aqueous MDEA and Aqueous MEG Systems at Ambient Pressure

\begin{tabular}{|c|c|c|c|c|}
\hline system & molar fraction, $x_{1}$ & property & temperature $(\mathrm{K})$ & source \\
\hline MDEA (1) & $0-1$ & density & $283.15-363.15$ & Bernal-García et al. $^{10}$ \\
\hline \multirow[t]{21}{*}{$\mathrm{H}_{2} \mathrm{O}(2)$} & $0.0165-1$ & density & $288.15-333.15$ & Al-Ghawas et al. ${ }^{11}$ \\
\hline & $0.0165-1$ & viscosity & $288.15-333.15$ & \\
\hline & $0.0364,0.0608$ & density & $303.15-333.15$ & $\mathrm{Li}$ and $\mathrm{Lie}^{12}$ \\
\hline & $0.0364-1$ & viscosity & $303.15-353.15$ & \\
\hline & $0.0165-1$ & density & $288.15-333.15$ & Paul and Mandal ${ }^{13}$ \\
\hline & $0.0165-1$ & viscosity & $288.15-333.15$ & \\
\hline & $0.1-1$ & density & $293.15-333.15$ & Yin et al. ${ }^{14}$ \\
\hline & $0.1-1$ & viscosity & $293.15-333.15$ & \\
\hline & $0-1$ & viscosity & $298.15-353.15$ & Teng et al. ${ }^{15}$ \\
\hline & $0-1$ & viscosity & $313.15-363.15$ & Bernal-García et al. ${ }^{16}$ \\
\hline & $0-1$ & viscosity & $303.15-323.15$ & Chowdhury et al. $^{18}$ \\
\hline & $0.0447-1$ & viscosity & $293.15-353.15$ & Pinto et al. ${ }^{17}$ \\
\hline & $0.0165-0.1313$ & viscosity & $333.15-373.15$ & Rinker et al. ${ }^{19}$ \\
\hline & 1 & density & $296.15-470.15$ & DiGuillo et al. $^{31}$ \\
\hline & 1 & viscosity & $293.15-424.15$ & \\
\hline & 1 & density & $298.15-323.15$ & Álvarez et al. ${ }^{32}$ \\
\hline & 1 & viscosity & $298.15-323.15$ & \\
\hline & 1 & viscosity & $298.15-343.15$ & Henni et al. ${ }^{33}$ \\
\hline & 1 & viscosity & $303.15-343.15$ & Baek et al. ${ }^{20}$ \\
\hline & 1 & viscosity & $303.15-353.15$ & Haghtalab and Shojaeian ${ }^{34}$ \\
\hline & 1 & viscosity & $303.15-313.15$ & Akbar and Murugesan ${ }^{35}$ \\
\hline MEG (1) & $0-1$ & density & 298.15 & Hayduk and Malik ${ }^{21}$ \\
\hline \multirow[t]{15}{*}{$\mathrm{H}_{2} \mathrm{O}(2)$} & $0-1$ & viscosity & 298.15 & \\
\hline & $0-1$ & density & $263.15-423.15$ & Bohne et al. ${ }^{22}$ \\
\hline & $0-1$ & viscosity & $263.15-373.15$ & \\
\hline & $0.25-0.75$ & density & $296.15-445.15$ & Sun and Teja ${ }^{23}$ \\
\hline & $0-1$ & viscosity & $284.15-449.15$ & \\
\hline & $0-1$ & density & $273.15-363.15$ & Afzal et al. ${ }^{26}$ \\
\hline & $0-0.72$ & density & 293.15 & Tsierkezos and Molinou ${ }^{36}$ \\
\hline & $0-0.72$ & viscosity & 293.15 & \\
\hline & $0-1$ & density & $293.15-353.15$ & Yang et al. ${ }^{24}$ \\
\hline & $0-1$ & viscosity & $293.15-353.15$ & \\
\hline & $0-1$ & density & $283.15-313.15$ & Tsierkezos and Molinou ${ }^{25}$ \\
\hline & $0-1$ & viscosity & $283.15-313.15$ & \\
\hline & $0-1$ & viscosity & 298.15 & Jerome et al. ${ }^{37}$ \\
\hline & $0-1$ & viscosity & 298.15 & Dunstan $^{38}$ \\
\hline & 1 & viscosity & $298.15-373.15$ & Rumble $^{39}$ \\
\hline
\end{tabular}

76 been reported at low temperatures, even down to $263 \mathrm{~K}, \mathrm{~K}^{22,24,26}$ 77 only Bernal-García et al. ${ }^{10}$ report densities at $283.15 \mathrm{~K}$ for pure $78 \mathrm{MDEA}$ and its aqueous solutions. We have not found reported 79 viscosities of pure MDEA or aqueous MDEA in the existing 80 literature at such low temperature.

81 In this work, density and viscosity measurements of the binary 82 system MDEA-MEG and the ternary system MDEA-MEG$83 \mathrm{H}_{2} \mathrm{O}$ are presented in the temperature range of $T=283.15-$ $84353.15 \mathrm{~K}$ and at a pressure of $0.1020 \mathrm{MPa}$. The binary system 85 was studied in the whole concentration range, from pure MDEA 86 to pure MEG. For the ternary system of aqueous MDEA$87 \mathrm{MEG}-\mathrm{H}_{2} \mathrm{O}$, we varied the water concentration from 5 to $50 \mathrm{wt} \%$ 88 to demonstrate the impact of water content on the physical 89 properties of the amine-glycol system studied. Both density and 90 viscosity were modeled for the pure components and binary and 91 ternary systems using the data obtained in this work as well as 92 the data presented in Table 1.

\section{EXPERIMENTAL AND COMPUTATIONAL METHODS}

93 2.1. Materials. Information on the chemicals used is 94 provided in Table 2 . The chemicals were used as received from the supplier without further purification. For the aqueous 95 mixtures composed of MDEA-MEG- $\mathrm{H}_{2} \mathrm{O}$, deionized water 96 was used. The solutions were prepared gravimetrically in a 97 METTLER PM1200 scale with an accuracy of $1 \times 10^{-6} \mathrm{~kg}$, and 98 MDEA concentration was verified for each system by acid-base 99 titration. Magnetic stirring prior to measurements for at least $8 \mathrm{~h} \quad 100$ ensured solution homogeneity.

2.2. Experimental Methods. 2.2.1. Density Measure- 102 ments. The densities of all solutions were measured with an 103 Anton Paar Density Meter DMA 4500M. Millipore water and 104 dry air were used for the calibration of this apparatus, as 105 explained by Hartono et al., ${ }^{40}$ whereas pure water, MDEA, and 106 MEG were used as reference fluids for the apparatus validation. 107 We studied the repeatability of the density measurements 108 (set A) at selected temperatures at low and high concentrations 109 of MDEA-MEG, as well as at $353.15 \mathrm{~K}$ for the aqueous system 110 due to the risk of water vaporization. A reproducibility study 111 (set C) was also performed by preparing fresh solutions and 112 experimentally determining the density of the pure components 113 and the binary system at low and high concentrations. The 114 results show excellent repeatability and reproducibility with 115 


\section{Table 2. Chemical Sample Table}

\begin{tabular}{llrr}
\multicolumn{1}{c}{ component } & \multicolumn{1}{c}{ IUPAC name } & \multicolumn{1}{c}{ CAS } & \multicolumn{1}{c}{ supplier } \\
N-methyldiethanolamine (MDEA) & 2-[2-hydroxyethyl(methyl)amino] ethanol & $105-59-9$ & Sigma-Aldrich \\
monoethylene glycol (MEG) & ethane-1,2-diol & $107-21-1$ & Sigma-Aldrich \\
\hline
\end{tabular}

116 average absolute relative deviations (AARDs) equal to 0.01 and $1170.02 \%$, respectively.

118 2.2.2. Viscosity Measurements. Viscosity measurements 119 were performed in a Lovis $2000 \mathrm{M}$ microviscometer, connected 120 in series to the density meter. The sample is introduced to a 121 temperature-controlled capillary block with an accuracy of $0.02 \mathrm{~K}$, 122 where the Hoeppler's falling ball method is employed. In our 123 experiments, a capillary of a $1.59 \times 10^{-3} \mathrm{~m}$ diameter with a gold 124 ball was used, allowing for the measurement of viscosities up to 125 approximately $60 \mathrm{mPa}$ s. The apparatus validation is presented 126 in Section 3. The validation revealed an AARD from the 127 reference liquid value of $2.88 \%$. The repeatability (set A) and repro128 ducibility (set C) of the viscosity measurements were studied 129 similarly to density measurements, and the AARDs were 0.76 and $1300.69 \%$, respectively.

131 An Xsample $452 \mathrm{H}$ sample filling module is integrated into the 132 density meter and microviscometer for automatic sampling, 133 cleaning, and drying. The measurements always started with an 134 air check and measurement of Millipore water samples, which 135 were distributed in approximately every other three samples, 136 allowing for a continuous check of the results as well as an 137 additional cleaning medium.

138 For viscosities outside the limits of the available capillary in 139 the microviscometer, an Anton Paar MCR 100 rheometer with a 140 double-gap measuring cell (DG-26.7) was used. A detailed 141 description of the apparatus and experimental and calibration 142 procedure is given by Hartono et al. ${ }^{40}$ The measurement 143 repeatability was studied for all systems at $283.15 \mathrm{~K}$, and we 144 concluded that the repeatability of the instrument is good since 145 the maximum absolute relative deviation (MARD) is $2.05 \%$ and 146 the AARD is $0.5 \%$. Solutions measurable in the microviscometer 147 were also measured in the rheometer to determine the viscosity 148 reproducibility with the two different instruments. We con149 ducted the study primarily at $283.15 \mathrm{~K}$ and calculated a $2.72 \%$ 150 MARD and $1.07 \%$ AARD.

151 In all our experiments, at least two measurements were taken 152 and the average is reported as the measured property of the 153 solution. Moreover, acid-base titration was employed to deter154 mine the amine concentration of samples also after the measure155 ments to ensure that no vaporization had occurred. The concen156 tration of all samples remained unchanged even after the 157 experiments conducted at $353.15 \mathrm{~K}$.

158 2.3. Computational Methods. 2.3.1. Model Parametriza159 tion. The parametrization procedure has been carried following 160 the particle swarm optimization algorithm described by Poli 161 et al. ${ }^{41}$ and Ghosh et al. ${ }^{42}$ and previously successfully implemented 162 by Evjen et al. ${ }^{43}$ and Pinto and Svendsen. ${ }^{44}$ As before, the lbest 163 topology was chosen with $\omega=0.7298$ as the inertia factor and $164 \varphi_{1}=\varphi_{2}=1.49618$ as acceleration coefficients. The objective 165 function $\epsilon$ to be minimized is given by eq 1 , where $y$ is the output 166 one is set to estimate, $u$ is a set of input variables, and $\theta$ is a set of 167 model parameters. NP is the total number of points used for the 168 parametrization routine.

169

$$
\epsilon(u, y, \boldsymbol{\theta}))=\sum_{i=1}^{\mathrm{NP}} \frac{\left(y_{i}-\hat{y}_{i}(u, \boldsymbol{\theta})\right)^{2}}{y_{i} \cdot \hat{y}_{i}(u, \boldsymbol{\theta})}
$$

Furthermore, the quality of the fitting has been evaluated by two 170 complementary criteria: the average absolute relative deviation 171 (AARD) and the maximum absolute deviation (MAD) as 172 defined by eqs 2 and 3

$$
\begin{aligned}
& \mathrm{AARD}=\frac{100}{\mathrm{NP}} \cdot \sum_{i=1}^{\mathrm{NP}}\left|\frac{y_{i}-\hat{y}_{i}}{y_{i}}\right| \\
& \mathrm{MAD}=\max (|y-\hat{y}|)
\end{aligned}
$$

The same overall parametrization procedure has been applied 176 for the modeling of both density and viscosity. In general lines, 177 one initially needs to estimate the properties of single compo- 178 nents. The properties of binaries and ternaries are then calcu- 179 lated by the use of a simple mixing rule and an additional term 180 that accounts for excess properties. In this work, the fitting is 181 carried over the global data set, meaning that unitary, binary, and 182 ternary data sets are all coupled together in the evaluation of the 183 objective function $\epsilon$ and accounted for in the AARD and in the 184 $\mathrm{MAD}$ calculation. However, it is a good optimization practice to 185 fit the excess property models first to each individual binary data 186 set, thus generating a periphery of initial guesses for the fitting of 187 the global data set. This has been the procedure carried through- 188 out this study. A list of the symbols used in the remainder of this 189 work is given in the nomenclature provided at the end of the 190 article.

2.3.2. Modeling of Density. The typical approach employed 192 for the estimation of multicomponent system densities goes 193 through the modeling of excess molar volumes $\left(v^{\mathrm{E}}\right)$. Once the $v^{\mathrm{E}} 194$ of a mixture is calculated, its density can be recovered by eq 4. 195

$$
\rho=\frac{\sum_{i=1}^{\mathrm{NC}} x_{i} \cdot \mathrm{MW}_{i}}{v^{\mathrm{E}}+\sum_{i=1}^{\mathrm{NC}} \frac{x_{i} \cdot \mathrm{MW}_{i}}{\rho_{i}}}
$$

Following the example of Pinto et al., ${ }^{45}$ a modified Rackett 197 equation of the form shown in eqs 5-7 was employed for the 198 calculation of $\hat{\rho}_{i}$. This calculation requires the estimation of 199 single molar volumes in eq 5 using the Rackett compressibility 200 factor $Z_{\mathrm{RA}, i}$ described in eq 6 . The parameters in these equations 201 are the critical temperature $T_{\mathrm{C}, i}$ and critical pressure $p_{\mathrm{C}, i}$ for each 202 pure component and the reduced temperature and pressure. 203 Furthermore, three parameters $\left(\hat{A}_{i}, \hat{B}_{i}\right.$, and $\left.\hat{C}_{i}\right)$ have to be fitted 204 for the obtention of $Z_{\mathrm{RA}, i}$.

$$
\begin{aligned}
& \hat{v}_{i}(p, T)=\frac{\mathrm{R} \cdot T_{\mathrm{C}, i}}{p_{\mathrm{C}, i}} \cdot \hat{Z}_{\mathrm{RA}, i}^{1+\left(1-T_{\mathrm{r}, i}\right)^{2 / 7}} \\
& \hat{Z}_{\mathrm{RA}, i}(p, T)=\exp \left[\hat{\mathrm{A}}_{i}+\frac{\hat{B}_{i}}{p_{\mathrm{r}, i}}+\hat{C}_{i} \ln \left(T_{\mathrm{r}, i}\right)\right] \\
& \hat{\rho}_{i}(p, T)=\frac{\mathrm{MW}_{i}}{\hat{v}_{i}}
\end{aligned}
$$

The estimation of the single-component molar volumes $\hat{v}_{i}$ is 209 followed by the estimation of the excess properties $\hat{v}^{\mathrm{E}}$ of binary 210 and ternary mixtures. In the previous work carried out by Evjen 211 
212 et al., ${ }^{43}$ the Redlich-Kister (RK) equation fulfilled this duty. 213 However, as seen in that study, the RK equation demands that at 214 least six parameters are fitted for each binary mixture so that a 215 good agreement between experimental and estimated densities 216 is obtained. These binary estimations must additionally be 217 coupled with an extra $\hat{v}^{\mathrm{E}}$ model for the estimation of ternary 218 densities. ${ }^{46,47}$ Such a correction demands additional parameters 219 and fittings in the forms proposed differently by several distinct 220 authors, like Cibulka, ${ }^{48}$ Nagata and Tamura, ${ }^{49}$ Redlich and 221 Kister, ${ }^{50}$ and Singh et al. ${ }^{51}$ Most of these models have at least 222 three extra parameters, meaning that $6 \cdot \mathrm{NC}+3=21$ empirical 223 parameters must be found for the description of the density of 224 ternary solutions. This poses the disadvantages of having to 225 choose one among several $\hat{v}^{\mathrm{E}}$ models in the literature and fitting 226 an unordinary number of coefficients. This also means that the 227 quality of the ternary data fitting is wholly dependent on the 228 quality of the binary data fitting.

229 An alternative to this has been suggested by Pinto and 230 Knuutila $^{52}$ for the direct fitting of ternary density data. This 231 model, henceforth called the NRTL-DVOL, is explicitly based 232 on the nonrandom two-liquid (NRTL) model and has the form 233 outlined in eqs $8-11$.

$$
\begin{aligned}
& \hat{v}^{\mathrm{E}}(x, T)=R \cdot T \cdot \sum_{i=1}^{\mathrm{NC}} x_{i} \cdot \frac{\sum_{j=1}^{\mathrm{NC}} \hat{\tau}_{j i} \cdot \hat{G}_{j i} \cdot x_{j}}{\sum_{k=1}^{\mathrm{NC}} \hat{G}_{k i} \cdot x_{k}} \\
& \hat{G}_{i j}(T)=\exp \left(-\alpha_{i j} \cdot \hat{\tau}_{i j}\right) \\
& \hat{\tau}_{i j}(T)=\hat{a}_{i j}+\frac{\hat{b}_{i j}}{T} \\
& \hat{a}_{i i}=0 ; \hat{b}_{i i}=0 ; \hat{\alpha}_{i j}=\hat{\alpha}_{j i}
\end{aligned}
$$

238 The expressions shown in eqs 8-11 demand the fitting of $\hat{a}_{i j}$ and $239 \hat{b}_{i j}$. Meanwhile, $R$ is a fixed parameter of the model and its value is $240 R=6.48803$. The nonrandomness parameter $\alpha_{i j}$ is set alterna241 tively at $\alpha_{i j}=0.1,0.2$, or 0.3 , and the optimization routines are 242 performed once for each of these values. In this work, a global $\alpha_{i j}$ $243=\alpha$ was implemented for each study, meaning that a single $\hat{\alpha}$ was 244 chosen for the binary-ternary systems instead of one for each 245 binary.

246 2.3.3. Modeling of Viscosity. Similar to that of density, the 247 modeling of the viscosity requires the "excess viscosity" of the 248 mixture or more correctly the viscosity deviations from ideality 249 upon mixing. In this work, viscosity deviations $\Delta \eta$ were calcu250 lated from the experimental measurements using eqs $12-13^{53,54}$

$$
\begin{aligned}
& \left.\ln \left(\eta^{\mathrm{id}}\right)\right)=\sum_{i=1}^{\mathrm{NC}} x_{i} \ln \left(\eta_{i}\right) \\
& \Delta \eta=\eta-\eta^{\mathrm{id}}
\end{aligned}
$$

253 where $\eta^{\text {id }}$ is the viscosity of the ideal mixture; $x_{i}$ and $\eta_{i}$ are the 254 molar fraction and viscosity of the pure component $i$, 255 respectively; $\eta$ is the measured viscosity of the mixture; and $256 \Delta \eta$ is the viscosity deviation upon mixing.

257 There are several approaches for modeling the viscosity of 258 binary liquid mixtures. However, only the models of Song et al. ${ }^{55}$ 259 and Pinto and Svendsen ${ }^{44}$ offer an easy extension toward the 260 calculation of ternary mixtures. The former is usually called the 261 Aspen liquid mixture viscosity model, whereas the latter was 262 named the NRTL-DVIS model. Both of them are reliant on 263 good estimates of pure component viscosities. Therefore, the viscosities of pure MDEA and MEG were fitted to the Vogel 264 equation, which has a generic form shown in eq 14 .

$$
\ln \left(\hat{\eta}_{i}(T)\right)=\hat{A}_{i}+\frac{\hat{B}_{i}}{T-\hat{C}_{i}}
$$

Meanwhile, the viscosity of pure water can be estimated by the 267 correlation of Bingham and Jackson $^{56}$ given in eqs 15 and 16. 268

$$
\begin{aligned}
\varphi_{\mathrm{H}_{2} \mathrm{O}}(T)= & 2.1482 \cdot[(T-281.585) \\
& \left.+\sqrt{8078.4+(T-281.585)^{2}}\right]-120 \\
\hat{\eta}_{\mathrm{H}_{2} \mathrm{O}}(T)= & \frac{100}{\varphi_{\mathrm{H}_{2} \mathrm{O}}}
\end{aligned}
$$

The viscosity of mixtures is estimated by the addition of an 271 excess viscosity term, different from the one displayed in eqs 12272 and 13, as shown in eq 17. Following the initial suggestion of 273 Song et al., ${ }^{55}$ the mass fractions $w_{i}$ are better weights for the 274 mixture calculations than the molar fractions $x_{i}$.

$$
\ln (\hat{\eta}(w, T))=\sum_{i=1}^{\mathrm{NC}} w_{i} \cdot \ln \left(\hat{\eta}_{i}(T)\right)+\ln \left(\hat{\eta}^{\mathrm{E}}(w, T)\right)
$$

Moreover, the form that this excess term $\hat{\eta}^{\mathrm{E}}$ can take is what 277 differs the Aspen liquid mixture viscosity model from the NRTL- 278 DVIS model. Following the Aspen liquid mixture viscosity 279 model, this term is calculated by eqs $18-21$. These equations 280 require that four different sets of parameters, $\hat{a}_{i j}, \hat{b}_{i j}, \hat{c}_{i j}$, and $\hat{d}_{i j}$, are 281 estimated for each binary pair.

$$
\begin{aligned}
& \ln \left(\hat{\eta}^{\mathrm{E}}(w, T)\right)=\sum_{i=1}^{\mathrm{NC}} \sum_{j>i}^{\mathrm{NC}} \hat{k}_{i j} \cdot w_{i} \cdot w_{j} \ln \left(\hat{\eta}_{i j}\right) \\
& +\sum_{i=1}^{\mathrm{NC}} w_{i} \cdot\left[\sum_{j \neq i}^{\mathrm{NC}} w_{j} \cdot\left(\hat{l}_{i j} \ln \left(\hat{\eta}_{i j}\right)\right)^{1 / 3}\right]^{3} \\
& \ln \left(\hat{\eta}_{i j}\right)=\frac{\left|\ln \left(\hat{\eta}_{i}\right)-\ln \left(\hat{\eta}_{j}\right)\right|}{2} \\
& \hat{k}_{i j}(T)=\hat{a}_{i j}+\frac{\hat{b}_{i j}}{T} \\
& \hat{l}_{i j}(T)=\hat{c}_{i j}+\frac{\hat{d}_{i j}}{T}
\end{aligned}
$$

Similarly, the NRTL-DVIS model also requires that 12287 parameters be estimated. Its form is very similar to that of the 288 NRTL-DVOL since both come from the same approach of 289 modeling excess properties with the general shape of the 290 NRTL excess Gibbs energy equation. The model is described by 291 eqs 22-25.

\section{2}

$$
\begin{aligned}
& \ln \left(\hat{\eta}^{\mathrm{E}}(w, T)\right)=R \cdot \sum_{i=1}^{\mathrm{NC}} w_{i} \cdot \frac{\sum_{j=1}^{\mathrm{NC}} \hat{\tau}_{j i} \cdot \hat{G}_{j i} \cdot w_{j}}{\sum_{k=1}^{\mathrm{NC}} \hat{G}_{k i} \cdot w_{k}} \\
& \hat{G}_{i j}(T)=\exp \left(-\alpha_{i j} \cdot \hat{\tau}_{i j}\right) \\
& \hat{\tau}_{i j}(T)=\hat{a}_{i j}+\frac{\hat{b}_{i j}}{T}
\end{aligned}
$$


Table 3. Experimental and Indicative Literature Values of the Density $\rho / \mathrm{kg} \mathrm{m}^{-3}$ for Pure Water, MEG, and MDEA at Temperatures $T=283.15-353.15 \mathrm{~K}$ and Pressure near $p=0.1 \mathrm{MPa}$

\begin{tabular}{|c|c|c|c|c|c|c|c|c|c|}
\hline \multirow[b]{3}{*}{$T / \mathrm{K}$} & \multicolumn{6}{|c|}{$\rho / \mathrm{kg} \mathrm{m}^{-3}$} & \multicolumn{3}{|c|}{$=$} \\
\hline & \multicolumn{3}{|c|}{ water } & \multicolumn{3}{|c|}{ MEG } & \multicolumn{3}{|c|}{ MDEA } \\
\hline & Spieweck and Bettin ${ }^{57}$ & Yang et al. ${ }^{24}$ & this work & Afzal et al. ${ }^{26}$ & Yang et al. $^{24}$ & this work & Bernal-García et al. ${ }^{10}$ & Al-Ghawas et al. ${ }^{11}$ & this work \\
\hline 283.15 & 999.699 & & 999.9 & 1120.23 & & 1120.0 & 1047.53 & & 1048.0 \\
\hline 298.15 & 997.043 & & 997.2 & 1109.77 & & 1109.9 & 1037.86 & 1037.4 & 1036.8 \\
\hline 313.15 & 992.212 & 992.2 & 992.3 & 1099.17 & 1093.6 & 1098.8 & 1026.52 & 1026.7 & 1025.4 \\
\hline 323.15 & 988.030 & 988.1 & 988.3 & 1092.02 & 1084.7 & 1091.6 & 1018.88 & 1019.4 & 1017.7 \\
\hline 333.15 & 983.191 & 983.2 & 983.5 & 1084.78 & 1076.4 & 1085.0 & 1011.43 & 1012.3 & 1010.0 \\
\hline 343.15 & 977.759 & 977.8 & 978.1 & 1077.42 & 1067.5 & 1077.6 & 1003.32 & & 1002.2 \\
\hline 353.15 & 971.785 & 971.8 & 972.3 & 1069.95 & 1060.0 & 1070.1 & 995.41 & & 994.6 \\
\hline $\operatorname{AARD}(\%)^{a}$ & & & 0.03 & & & 0.33 & & & 0.12 \\
\hline${ }^{a} \operatorname{AARD}(\%)=$ & $=\frac{100}{\mathrm{NP}} \sum_{i=1}^{\mathrm{NP}}\left|\frac{\rho_{i}^{\exp }-\rho_{i}^{\mathrm{lit}}}{\rho_{i}^{\mathrm{lit}}}\right|$ & & & & & & & & \\
\hline
\end{tabular}

Table 4. Experimental Values of Density $\rho / \mathrm{kg} \mathrm{m}^{-3}$ for $\{$ MDEA (1) + MEG (2) $\}$ as a Function of Weight Fraction $w$ and Temperature $T$ at Pressure $p=0.1020 \mathrm{MPa}^{a}$

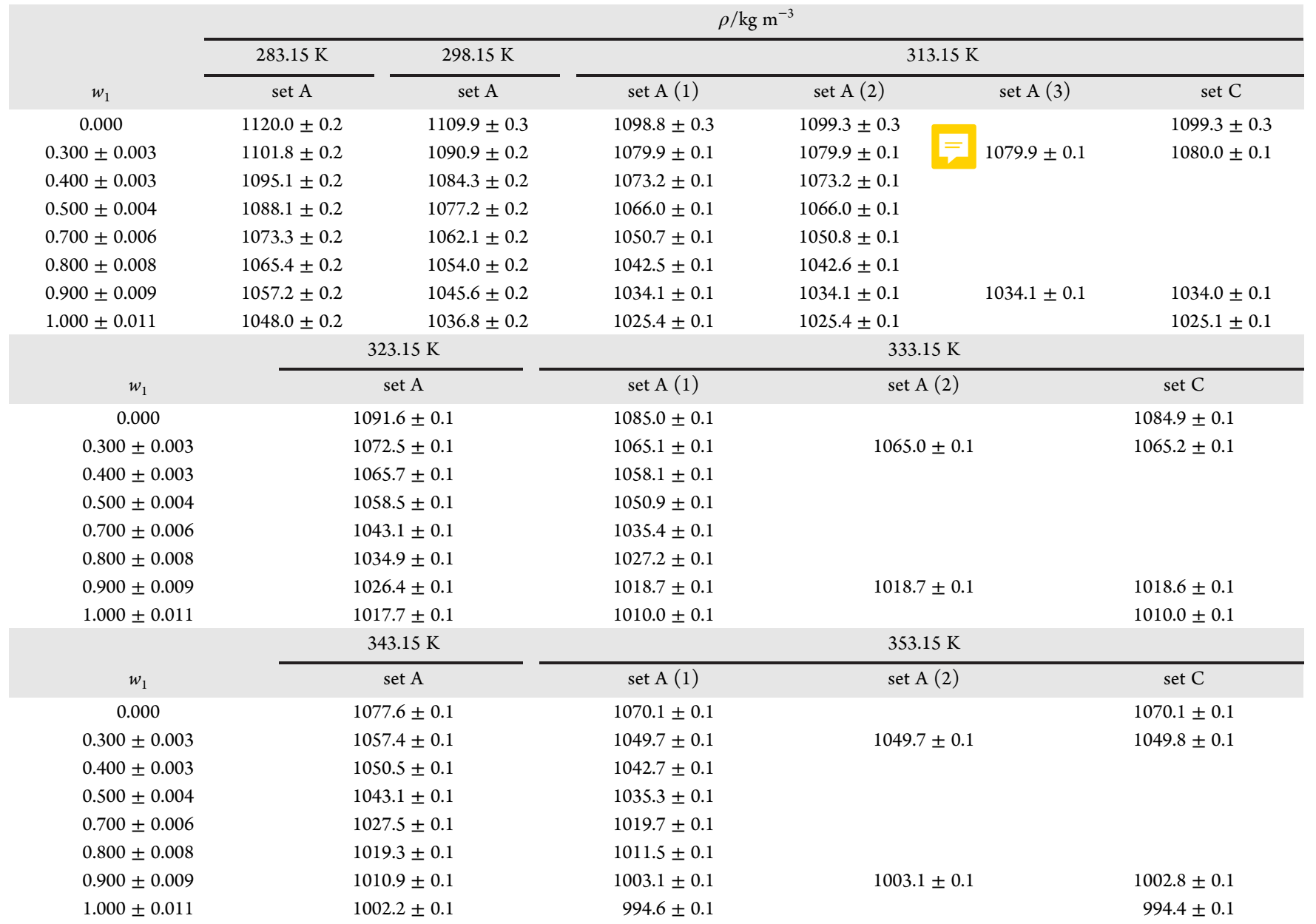

${ }^{a}$ Weight fractions and densities are reported with their expanded uncertainties ( 0.95 level of confidence). Expanded uncertainties not included above are $U(T)=0.02 \mathrm{~K}$ and $U(p)=0.0030 \mathrm{MPa}$.

$$
\hat{a}_{i i}=0 ; \quad \hat{b}_{i i}=0 ; \quad \hat{\alpha}_{i j}=\hat{\alpha}_{j i}
$$

297 All of the remarks made regarding the NRTL-DVOL model 298 apply to the NRTL-DVIS model. Once again, a value of $R=$ 2996.48803 was set as a fixed parameter of the equations, whereas $300 \alpha_{i j}=\alpha$ was set alternatively to $\alpha=0.1,0.2$, and 0.3 for each 301 optimization routine.

\section{RESULTS AND DISCUSSION}

The results of density $\rho$ and viscosity $\eta$ measurements 302 and modeling for the binary mixtures of MDEA-MEG and 303 the ternary mixtures of MDEA-MEG- $\mathrm{H}_{2} \mathrm{O}$ are presented 304 below.

3.1. Density. The densities of pure water, monoethylene 306 glycol, and methyldiethanolamine were measured and compared 307 
Table 5. Experimental Values of Density $\rho / \mathrm{kg} \mathrm{m}^{-3}$ for $\{$ MDEA (1) + MEG (2) + Water (3) $\}$ as a Function of Weight Fraction $w$ and Temperature $T$ at Pressure $p=0.1020 \mathrm{MPa}^{a}$

\begin{tabular}{|c|c|c|c|c|c|c|c|}
\hline & & \multicolumn{6}{|c|}{$\rho / \mathrm{kg} \mathrm{m}^{-3}$} \\
\hline & \multirow[b]{2}{*}{$w_{2}$} & $283.15 \mathrm{~K}$ & $298.15 \mathrm{~K}$ & \multicolumn{2}{|r|}{$313.15 \mathrm{~K}$} & \multirow{2}{*}{$\begin{array}{c}323.15 \mathrm{~K} \\
\text { set A }\end{array}$} & \multirow{2}{*}{$\begin{array}{c}333.15 \mathrm{~K} \\
\text { set A }\end{array}$} \\
\hline$w_{1}$ & & set $A$ & set $\mathrm{A}$ & \multicolumn{2}{|r|}{ set A } & & \\
\hline $0.050 \pm 0.002$ & $0.900 \pm 0.003$ & $1114.1 \pm 0.2$ & \multicolumn{2}{|l|}{$1103.7 \pm 0.3$} & $1093.1 \pm 0.1$ & $1086.4 \pm 0.6$ & $1079.1 \pm 0.7$ \\
\hline $0.900 \pm 0.013$ & $0.050 \pm 0.010$ & $1057.6 \pm 0.2$ & $1046.3 \pm 0.3$ & $=$ & $1034.8 \pm 0.1$ & $1027.5 \pm 0.6$ & $1019.8 \pm 0.7$ \\
\hline $0.300 \pm 0.003$ & $0.600 \pm 0.003$ & $1196.6 \pm 0.2$ & \multicolumn{2}{|c|}{$1086.1 \pm 0.3$} & $1075.1 \pm 0.1$ & $1068.2 \pm 0.6$ & $1060.7 \pm 0.7$ \\
\hline $0.600 \pm 0.006$ & $0.300 \pm 0.006$ & $1078.5 \pm 0.2$ & \multicolumn{2}{|c|}{$1067.6 \pm 0.3$} & $1056.3 \pm 0.1$ & $1049.1 \pm 0.6$ & $1041.5 \pm 0.7$ \\
\hline $0.100 \pm 0.002$ & $0.600 \pm 0.002$ & $1090.1 \pm 0.2$ & \multicolumn{2}{|l|}{$1080.5 \pm 0.3$} & $1070.3 \pm 0.1$ & $1063.4 \pm 0.6$ & $1056.8 \pm 0.7$ \\
\hline $0.300 \pm 0.003$ & $0.400 \pm 0.003$ & $1081.2 \pm 0.2$ & \multicolumn{2}{|l|}{$1071.2 \pm 0.3$} & $1060.9 \pm 0.1$ & $1053.8 \pm 0.6$ & $1047.1 \pm 0.7$ \\
\hline $0.600 \pm 0.006$ & $0.100 \pm 0.006$ & $1067.8 \pm 0.2$ & \multicolumn{2}{|l|}{$1057.4 \pm 0.3$} & $1046.5 \pm 0.1$ & $1039.4 \pm 0.6$ & $1031.7 \pm 0.7$ \\
\hline \multirow[t]{2}{*}{$0.250 \pm 0.002$} & $0.250 \pm 0.002$ & $1061.0 \pm 0.2$ & $1052.2 \pm 0.3$ & & $1043.2 \pm 0.1$ & $1036.6 \pm 0.6$ & $1030.5 \pm 0.7$ \\
\hline & & \multicolumn{2}{|c|}{$343.15 \mathrm{~K}$} & \multicolumn{4}{|c|}{$353.15 \mathrm{~K}$} \\
\hline$w_{1}$ & $w_{2}$ & \multicolumn{2}{|c|}{ set $A$} & \multicolumn{2}{|c|}{ set A (1) } & set A (2) & set $\mathrm{C}$ \\
\hline $0.050 \pm 0.002$ & $0.900 \pm 0.003$ & \multicolumn{2}{|c|}{$1071.8 \pm 0.7$} & \multicolumn{2}{|c|}{$1064.5 \pm 0.9$} & $1064.6 \pm 0.9$ & \\
\hline $0.900 \pm 0.013$ & $0.050 \pm 0.010$ & \multicolumn{2}{|c|}{$1012.0 \pm 0.7$} & \multicolumn{2}{|c|}{$1004.2 \pm 0.9$} & $1004.2 \pm 0.9$ & \\
\hline $0.300 \pm 0.003$ & $0.600 \pm 0.003$ & \multicolumn{2}{|c|}{$1053.2 \pm 0.7$} & \multicolumn{2}{|c|}{$1045.6 \pm 0.9$} & $1045.7 \pm 0.9$ & $1045.7 \pm 0.9$ \\
\hline $0.600 \pm 0.006$ & $0.300 \pm 0.006$ & 1033 & & 1025 . & \pm 0.9 & $1025.8 \pm 0.9$ & \\
\hline $0.100 \pm 0.002$ & $0.600 \pm 0.002$ & 1049 & & 1042. & \pm 0.9 & $1042.2 \pm 0.9$ & \\
\hline $0.300 \pm 0.003$ & $0.400 \pm 0.003$ & 1039 & & 1031. & \pm 0.9 & $1031.9 \pm 0.9$ & \\
\hline $0.600 \pm 0.006$ & $0.100 \pm 0.006$ & 1023 & & 1015 & \pm 0.9 & $1015.8 \pm 0.9$ & \\
\hline $0.250 \pm 0.002$ & $0.250 \pm 0.002$ & 1023 & & 1016. & \pm 0.9 & $1016.1 \pm 0.9$ & $1016.2 \pm 0.9$ \\
\hline
\end{tabular}

${ }^{a}$ Weight fractions and densities are reported with their expanded uncertainties ( 0.95 level of confidence). Expanded uncertainties not included above are $U(T)=0.02 \mathrm{~K}$ and $U(p)=0.0030 \mathrm{MPa}$.

308 to values from the literature for validation purposes. Our 309 measured densities were compared against the literature sources 310 presented in Table 1 and, to be more specific, against data 311 reported by Bernal-García et al., ${ }^{10}$ Hayduk and Malik, ${ }^{21}$ Yang 312 et al., ${ }^{24}$ Tsierkezos and Molinou, ${ }^{25}$ and Spieweck and Bettin ${ }^{57}$ 313 for water; data reported by Hayduk and Malik, ${ }^{21}$ Bohne et al., ${ }^{22}$ 314 Afzal et al., ${ }^{26}$ Yang et al., ${ }^{24}$ and Tsierkezos and Molinou ${ }^{25}$ for 315 MEG; and data reported by Bernal-García et al., ${ }^{10}$ Al-Ghawas 316 et al., ${ }^{11}$ Álvarez et al., ${ }^{32}$ Paul and Mandal, ${ }^{13}$ and Yin et al. ${ }^{14}$ for 317 MDEA. The average absolute relative deviation (AARD) is $3180.01 \%$ for water, $0.30 \%$ for MEG, and $0.10 \%$ for MDEA, demon319 strating that our measurements are in good agreement with the 320 data already reported in the literature. Indicative literature data 321 sets are given in Table 3, selected because they cover as many 322 temperatures studied in this work as possible. The AARDs using 323 those two sources for each component were found to be 0.03 , 3240.33 , and $0.12 \%$ for water, MEG, and MDEA, respectively.

325 Tables 4 and 5 show the measured densities in this work for 326 the nonaqueous and aqueous MEG-MDEA mixtures, respec327 tively, as a function of weight fraction $w$ and temperature $T$ at 328 ambient pressure. The expanded uncertainties with a 0.95 level 329 of confidence of composition and density are provided for each 330 system and temperature. In addition to the weight fractions, 331 molar fractions $x_{i}$ and the corresponding uncertainties can be 332 found in the Supporting Information. As mentioned earlier, the 333 repeatability of the density measurements is excellent, as one can 334 see in the results. It is observed that the density of the binary 335 mixtures of MDEA-MEG decreases with temperature and with 336 MDEA concentration. These trends are better illustrated in 337 Figure 1, presenting the experimental densities for the binary 338 system MDEA-MEG and the estimates generated by the 339 NRTL-DVOL model. Similar figures for MDEA- $\mathrm{H}_{2} \mathrm{O}$ and $340 \mathrm{MEG}-\mathrm{H}_{2} \mathrm{O}$ are provided in the Supporting Information. The 341 density of $\mathrm{MEG}-\mathrm{H}_{2} \mathrm{O}$ is similar to the one for MDEA-MEG, 342 whereas the one for the binary MDEA $-\mathrm{H}_{2} \mathrm{O}$ varies in the way

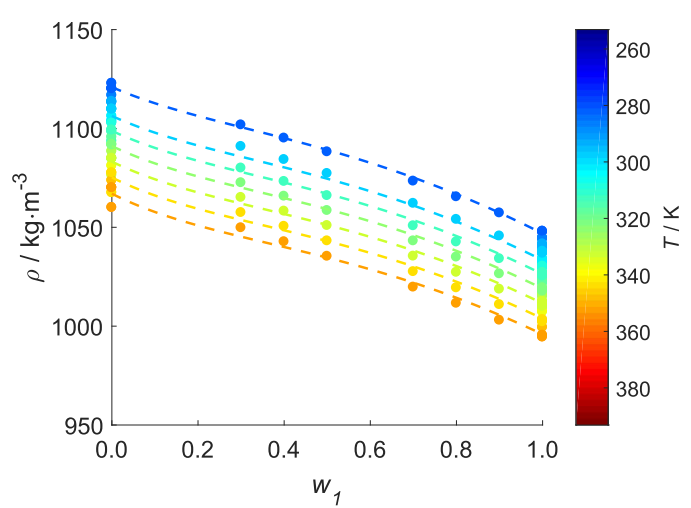

Figure 1. Binary data set of densities for $\{$ MDEA (1) + MEG (2) $\}$ and estimations generated by the NRTL-DVOL model. The temperature at which each experimental point (solid circle) was measured is colorcoded by the bar on the right side. The temperatures at which the estimates were made were $283.15 \mathrm{~K}$ (dark-blue dashed line), $298.15 \mathrm{~K}$ (capri-blue dashed line), $313.15 \mathrm{~K}$ (aqua dashed line), $323.15 \mathrm{~K}$ (green dashed line), $333.15 \mathrm{~K}$ (lime-green dashed line), $343.15 \mathrm{~K}$ (yellow dashed line), and $353.15 \mathrm{~K}$ (orange dashed line).

that it increases with MDEA concentration but only up to 343 approximately $w_{1}=0.7$ after which it starts decreasing. This 344 behavior is due to the excess molar volumes upon mixing of 345 MDEA and $\mathrm{H}_{2} \mathrm{O}$ and is discussed in detail in Section 3.3. The 346 trend of decreasing density with temperature and amine content 347 applies to the ternary systems as well, given that the amount of 348 water in the solution is constant. The generated density contour 349 plots for the ternary system can be found in the Supporting 350 Information.

351

As explained in Section 2, a modified Rackett equation was 352 employed for the fitting of the single-component data sets 353 shown in Table 1 . The results of the fitting are presented in 354 Table 6 and Figure 2. The values of MW, $T_{C}$, and $p_{C}$ were 355 obtained from Yaws. ${ }^{58}$ The fitting for water was not performed 356 
Table 6. Parameters and Results for the Fittings of the Modified Rackett Equation

\begin{tabular}{llll}
\multicolumn{1}{c}{ parameter } & \multicolumn{1}{c}{ MDEA } & \multicolumn{1}{c}{ MEG } & \multicolumn{1}{c}{ water $^{52}$} \\
$\mathrm{MW}\left(\mathrm{kg} \mathrm{kmol}^{-1}\right)$ & 119.16 & 62.07 & 18.02 \\
$T_{\mathrm{C}}(\mathrm{K})$ & 675 & 720 & 647.1 \\
$p_{\mathrm{C}}(\mathrm{MPa})$ & 3.88 & 8.20 & 22.064 \\
$\hat{A}$ & -1.4003 & -1.4021 & -1.4937 \\
$\hat{B}$ & $-3.0132 \times 10^{-6}$ & $-0.7670 \times 10^{-6}$ & $6.6495 \times 10^{-6}$ \\
$\hat{C}$ & -0.03542 & -0.02230 & -9.868 \\
$\mathrm{AARD}(\%)$ & 0.07 & 0.19 & 0.35 \\
$\operatorname{MAD}\left(\mathrm{kg} \mathrm{m}^{-3}\right)$ & 2.36 & 7.68 & 15.82 \\
\hline
\end{tabular}

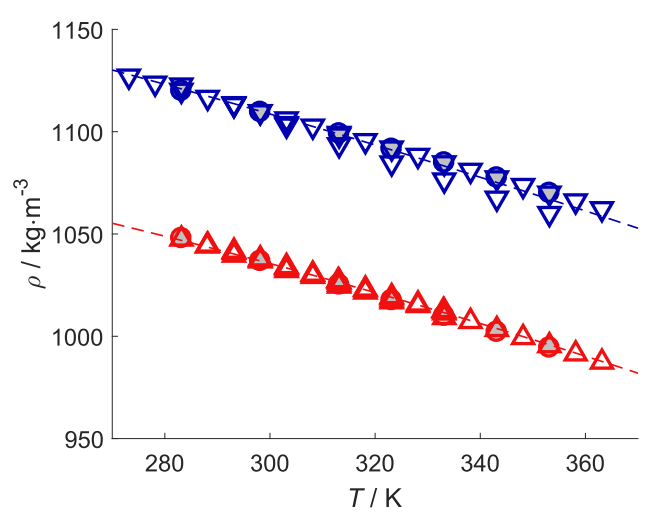

Figure 2. Experimental single-component density of MDEA both obtained in the literature (red open triangle up) and as produced in this work (red circle filled in gray) and of MEG both obtained in the literature (blue open triangle down) and as produced in this work (blue circle filled in gray), and corresponding estimations with the modified Rackett equation for MDEA (red dashed line) and MEG (blue dashed line).

357 in this study, but the parameters for its modified Rackett 358 equation were obtained from Pinto and Knuutila. ${ }^{52}$ As such, we 359 merely report the parameters obtained by these authors without 360 checking their significance, though it should be pointed out that 361 the parameter $\hat{B}$ obtained by Pinto and Knuutila ${ }^{52}$ of $6.6495 \times$ $36210^{-6}$ could be set to zero with no noticeable effects on the 363 performance of the model. Although the results for the fitting of 364 MEG are worse than those of MDEA, this is arguably due to the 365 scatter in experimental data found for MEG in the literature, as 366 evidenced by Figure 2. The density data of pure MEG reported 367 by Yang et al. ${ }^{24}$ is partially responsible for this scatter, as their 368 values are consistently lower than those obtained by other 369 researchers (see the bifurcation in the blue data points in 370 Figure 2), particularly at higher temperatures. However, the data 371 set from Yang et al. ${ }^{24}$ contains pure water density measurements 372 in excellent agreement with the literature, and their collection of 373 pure MEG density measurements is off by only $1 \%$ when com374 pared to other published data. Therefore, we have decided to 375 keep their data set in our parametrization procedure.

376 Table 7 shows the results for the fitting with the NRTL377 DVOL model. The fitting was done by minimizing the objective 378 function eq 1 with the entire data set of unitary, binary, and 379 ternary solutions. Moreover, since the parameters found for the 380 NRTL-DVOL fitting are valid for estimating binary as well as 381 ternary data, Table 7 shows first the AARD and MAD obtained 382 for the binaries and then that obtained for the global data set. 383 It can be seen that the AARDs are very small for the three 384 binaries and that the deviations for the MEG-water binary case 385 are the worst. This will be discussed further with the aid of 386 Figure 3. Overall, the fitting results are quite good and show that
Table 7. Parameters and Results for the NRTL-DVOL Equation Fitted for the Global Data Set

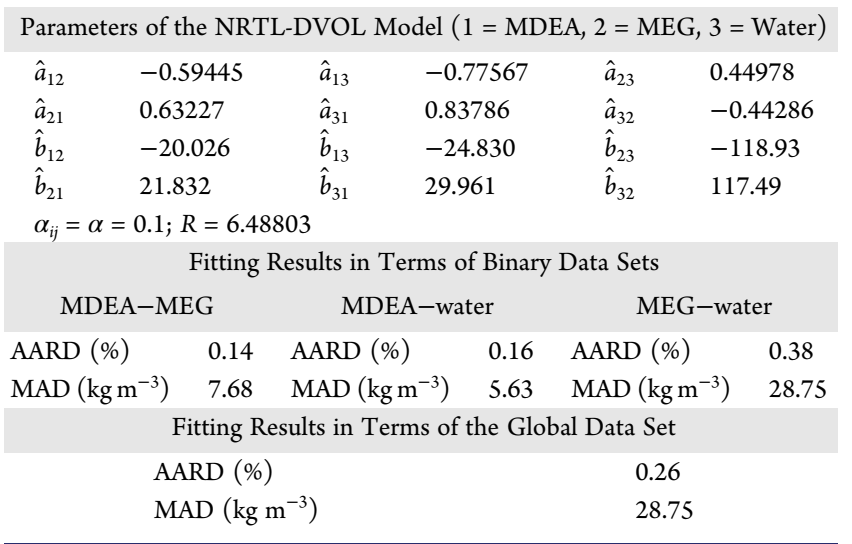

the densities of both binary and ternary mixtures can be 387 estimated with a high degree of confidence.

The parity plots exhibited in Figure 3a,b reinforce that the 389 fitting of the NRTL-DVOL model for the global data set is good, 390 with only a few remarkable features. One of them is the higher 391 deviations observed for binary data regarding MEG-water 392 mixtures (cyan cross), which account for the largest share in the 393 decoupling between model and experimental data. Figure 3a 394 evidences that this decoupling is the strongest at lower densities 395 or, conversely, at higher temperatures (Figure 3b). This can be 396 explained by the scatter of data points at these specific con- 397 ditions and by the original scatter of pure MEG data observed 398 already in Figure 2. Other decoupling trends, such as that for 399 MDEA-water binary mixtures at higher temperatures (green 400 asterisk), are an unfortunate consequence of fitting parameters 401 for such a wide range of temperatures and compositions. Never- 402 theless, for all systems, besides one MEG-water data point, the 403 deviations are not higher than $1 \%$. One can also observe the 404 absolute relative deviations (ARDs) between measured and 405 estimated values for ternary systems in Table S1 in the Supporting 406 Information.

3.2. Viscosity. The viscosities of pure water, monoethylene 408 glycol, and methyldiethanolamine were measured and compared 409 to values from the literature for validation purposes. At temper- 410 atures higher than $323.15 \mathrm{~K}$, it was not possible to measure the 411 viscosity of pure water. Similar to that of the density study, our 412 measured viscosities were compared against all of the literature 413 sources presented in Table 1 . The data used for the validation 414 are from Teng et al., ${ }^{15}$ Bernal-García et al., ${ }^{16}$ Chowdhury et al., ${ }^{18} 415$ Pinto et al., ${ }^{17} \mathrm{Li}$ and Lie, ${ }^{12}$ and Yin et al. ${ }^{14}$ for MDEA and from 416 Hayduk and Malik, ${ }^{21}$ Bohne et al., ${ }^{22}$ Tsierkezos and Molinou, ${ }^{25} 417$ Yang et al., ${ }^{24}$ Jerome et al., ${ }^{37}$ and Dunstan ${ }^{38}$ for MEG. For water, 418 the same references as previously mentioned for MEG validation 419 were used, in addition to Teng et al., ${ }^{15}$ Bernal-García et al., ${ }^{16}$ and 420 Chowdhury et al. ${ }^{18}$ The AARDs are $2.40,3.78$, and $2.71 \%$ for 421 water, MEG, and MDEA, respectively. The AARDs for viscosity 422 are higher than for density, indicating the more challenging 423 nature of viscosity measurements compared to the density ones. 424 The data obtained agree satisfactorily with the data already 425 reported in the literature, with the exception of pure MEG at 426 $283.15 \mathrm{~K}$. Indicative reference sources and their corresponding 427 AARDs are given in Table 8 .

The measured viscosities for the nonaqueous and aqueous 429 MDEA-MEG and corresponding expanded uncertainties with a 430 0.95 level of confidence are shown in Tables 9 and 10, respec- 431 tively. The repeatability of density measurements was excellent, 432 


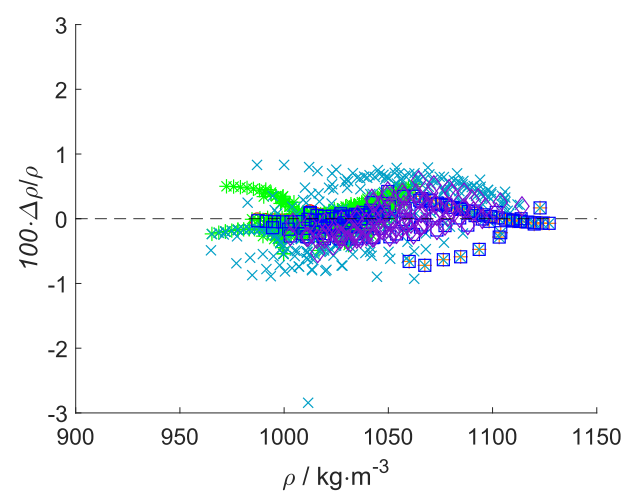

(a)

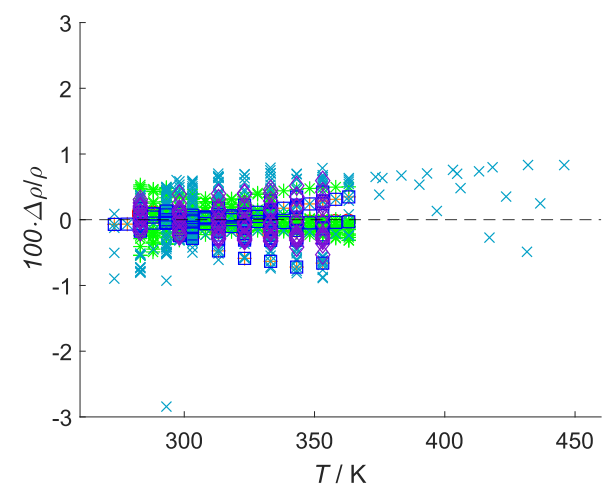

(b)

Figure 3. Deviations in terms of differences between experimental and estimated densities divided by experimental densities regarding estimations made with the NRTL-DVOL model, and how they vary the experimental densities themselves (a) and with temperature (b). The data sets are distributed in terms of pure MDEA data (red open circle), pure MEG data (orange plus), binary MDEA-water data (green asterisk), binary MEGwater data (cyan cross), binary MDEA-MEG data (blue open square), and ternary data (purple open diamond).

Table 8. Experimental and Indicative Literature Values of Viscosity $\eta / \mathrm{mPa}$ s for Pure Water, MEG, and MDEA at Temperatures $T=283.15-353.15 \mathrm{~K}$ and Pressure near $p=0.1 \mathrm{MPa}$

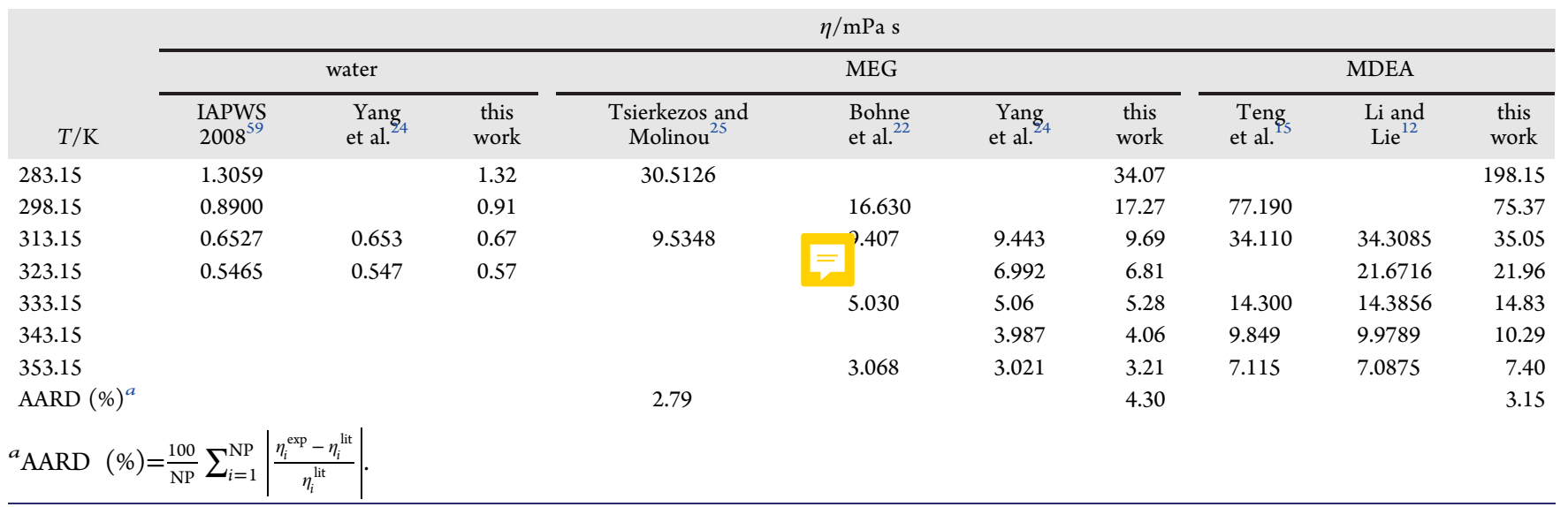

Table 9. Experimental Values of Viscosity $\eta / \mathrm{mPa} s$ for $\{$ MDEA (1) + MEG (2) $\}$ as a Function of Weight Fraction $w$ and Temperature $T$ at Pressure $p=0.1020 \mathrm{MPa}^{a}$

\begin{tabular}{|c|c|c|c|c|c|}
\hline \multirow[b]{2}{*}{$T / \mathrm{K}$} & & & \multicolumn{3}{|c|}{$\eta / \mathrm{mPa} \mathrm{s}$} \\
\hline & \multicolumn{2}{|c|}{$w_{1}$} & set $\mathrm{A}$ & set B (1) & set B (2) \\
\hline \multirow[t]{8}{*}{283.15} & \multicolumn{2}{|c|}{0.000} & $34.40 \pm 4.52$ & $33.92 \pm 4.06$ & $33.88 \pm 4.06$ \\
\hline & \multicolumn{2}{|c|}{$0.300 \pm 0.003$} & & $64.34 \pm 4.10$ & $64.37 \pm 4.10$ \\
\hline & \multicolumn{2}{|c|}{$0.400 \pm 0.003$} & & $80.69 \pm 4.06$ & $80.69 \pm 4.06$ \\
\hline & \multicolumn{2}{|c|}{$0.500 \pm 0.004$} & & $99.66 \pm 4.08$ & \\
\hline & \multicolumn{2}{|c|}{$0.700 \pm 0.006$} & & & \\
\hline & \multicolumn{2}{|c|}{$0.800 \pm 0.008$} & & $164.27 \pm 4.27$ & \\
\hline & \multicolumn{2}{|c|}{$0.900 \pm 0.009$} & 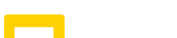 & $181.33 \pm 4.42$ & \\
\hline & \multicolumn{2}{|c|}{$1.000 \pm 0.011$} & $=$ & $197.93 \pm 4.20$ & $198.37 \pm 4.20$ \\
\hline$T / \mathrm{K}$ & \multicolumn{2}{|c|}{$w_{1}$} & set $\mathrm{A}$ & set B (1) & set B (2) \\
\hline \multirow[t]{8}{*}{298.15} & \multicolumn{2}{|c|}{0.000} & $17.28 \pm 1.08$ & & $17.25 \pm 1.08$ \\
\hline & \multicolumn{2}{|c|}{$0.300 \pm 0.003$} & $30.43 \pm 1.08$ & & \\
\hline & \multicolumn{2}{|c|}{$0.400 \pm 0.003$} & $36.57 \pm 1.08$ & & \\
\hline & \multicolumn{2}{|c|}{$0.500 \pm 0.004$} & $43.44 \pm 1.09$ & $43.65 \pm 2.61$ & \\
\hline & \multicolumn{2}{|c|}{$0.700 \pm 0.006$} & & $58.07 \pm 2.61$ & \\
\hline & \multicolumn{2}{|c|}{$0.800 \pm 0.008$} & & $66.59 \pm 2.62$ & \\
\hline & \multicolumn{2}{|c|}{$0.900 \pm 0.009$} & & $69.21 \pm 2.61$ & \\
\hline & \multicolumn{2}{|c|}{$1.000 \pm 0.011$} & & $75.87 \pm 2.62$ & $74.87 \pm 1.08$ \\
\hline $\mathrm{T} / \mathrm{K}$ & $w_{1}$ & set A (1) & set A (2) & set $A(3)$ & set $\mathrm{C}$ \\
\hline \multirow[t]{4}{*}{313.15} & 0.000 & $9.42 \pm 1.06$ & $9.82 \pm 1.06$ & & $9.83 \pm 1.06$ \\
\hline & $0.300 \pm 0.003$ & $15.74 \pm 1.04$ & $15.87 \pm 1.04$ & $15.87 \pm 1.04$ & $16.07 \pm 1.04$ \\
\hline & $0.400 \pm 0.003$ & $18.43 \pm 1.04$ & $18.61 \pm 1.04$ & & \\
\hline & $0.500 \pm 0.004$ & $21.20 \pm 1.06$ & $21.58 \pm 1.06$ & $21.97 \pm$ & \\
\hline
\end{tabular}


Table 9. continued

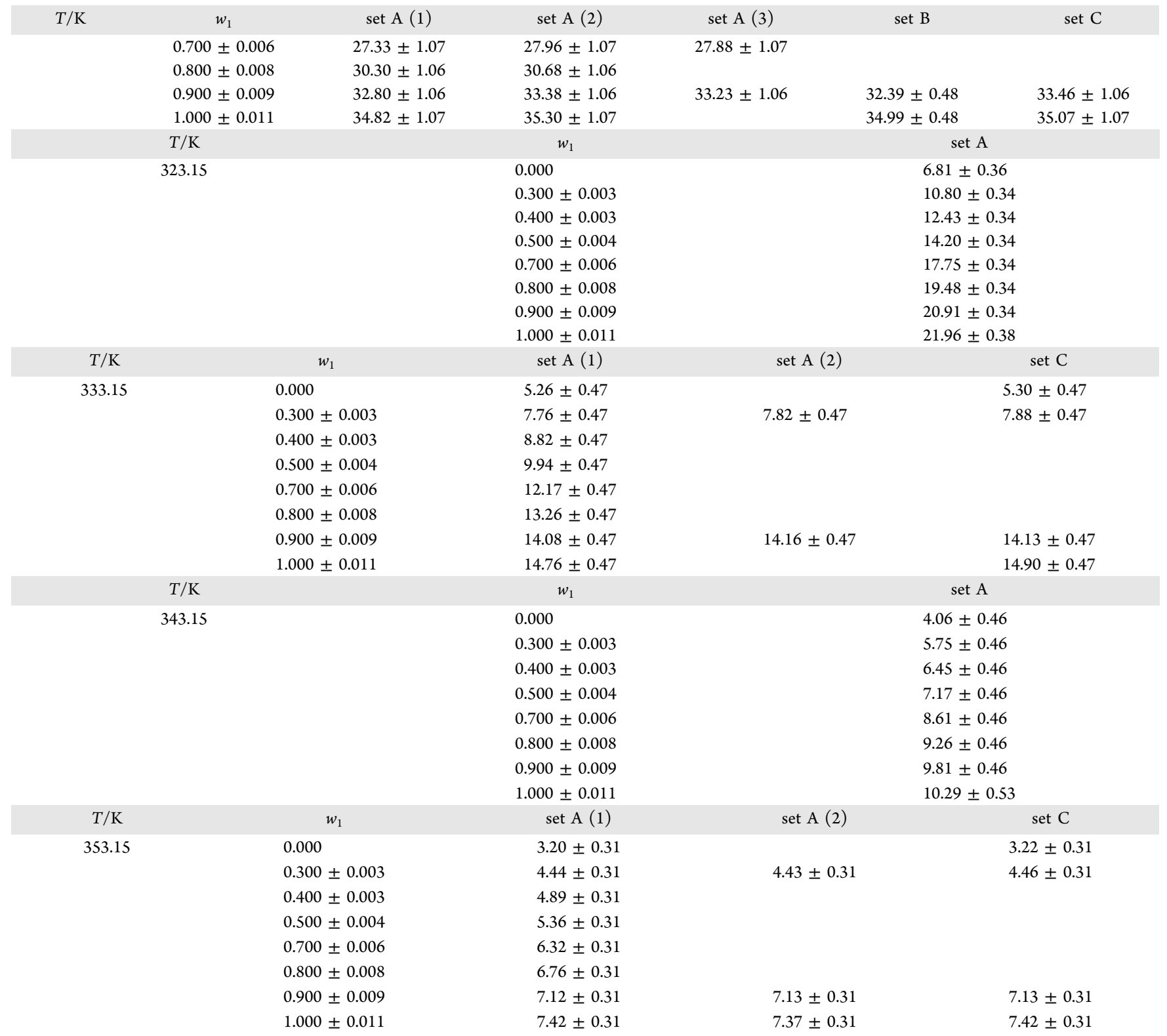

${ }^{a}$ Weight fractions and viscosities are reported with their expanded uncertainties ( 0.95 level of confidence). Expanded uncertainties not included above are $U(T)=0.02 \mathrm{~K}$ and $U(p)=0.0030 \mathrm{MPa}$.

433 whereas the one for viscosity is lower, though still satisfactory. 434 As presented earlier in Section 2, set A consists of the mea435 surements conducted in the microviscometer, set B consists of 436 the ones conducted in the rheometer, and set $\mathrm{C}$ includes all of 437 the measurements performed to study the reproducibility of the 438 obtained data.

439 As expected, viscosity increases as temperature decreases. 440 Actually, a rather dramatic increase with temperature is observed 441 especially for MDEA, exhibiting a viscosity of $7.4 \mathrm{mPa} \mathrm{s}$ at $442353.15 \mathrm{~K}$ and a viscosity of $198.1 \mathrm{mPa}$ s at $283.15 \mathrm{~K}$. The vari443 ation of viscosity for MEG at the temperature limits of the study 444 is far smaller than for MDEA. The same temperature effect is 445 shown for the multicomponent systems, whose viscosity is also 446 increasing with increasing amine concentration. The binary 447 system MDEA- $\mathrm{H}_{2} \mathrm{O}$ exhibits its maximum viscosity value for 448 MDEA concentration of approximately $95 \mathrm{wt} \%$ and then 449 decreases (see the Supporting Information for a graphical 450 presentation). Viscosity extremums (minimum, maximum, or both) are not uncommon, ${ }^{60}$ and several authors have observed 451 such behavior in amine-water systems. ${ }^{15,16,18,45,61}$ The lower 452 the temperature is, the more pronounced the maximum in the 453 viscosity curve is. This behavior is not followed for the MDEA- 454 MEG or MEG $-\mathrm{H}_{2} \mathrm{O}$ binary system, as indicated in Figures 4455 and S5, which show the binary plots generated by comparing 456 the fitted NRTL-DVIS model and real experimental data. 457 The observed viscosity behavior is further discussed in 458 Section 3.3.

459

According to the modeling procedure described in the 460 previous section, the Vogel equation was employed for the 461 estimation of the pure component viscosity. The results for the 462 parametrization of the Vogel equation, presented in Table 11, 463 show that the viscosities of the pure components are predicted 464 with a satisfactory accuracy. Although the scatter observed for 465 density data is not seen in the viscosity data, the huge variation of 466 viscosity values with temperature (see Figure 5) generates 467 AARDs worse than those observed for the fitting of density 468 
Table 10. Experimental Values of Viscosity $\eta / \mathrm{mPa}$ s for $\{$ MDEA (1) + MEG (2) + Water (3) $\}$ as a Function of Weight Fraction W and Temperature $T$ at Pressure $p=0.1020 \mathrm{MPa}^{a}$

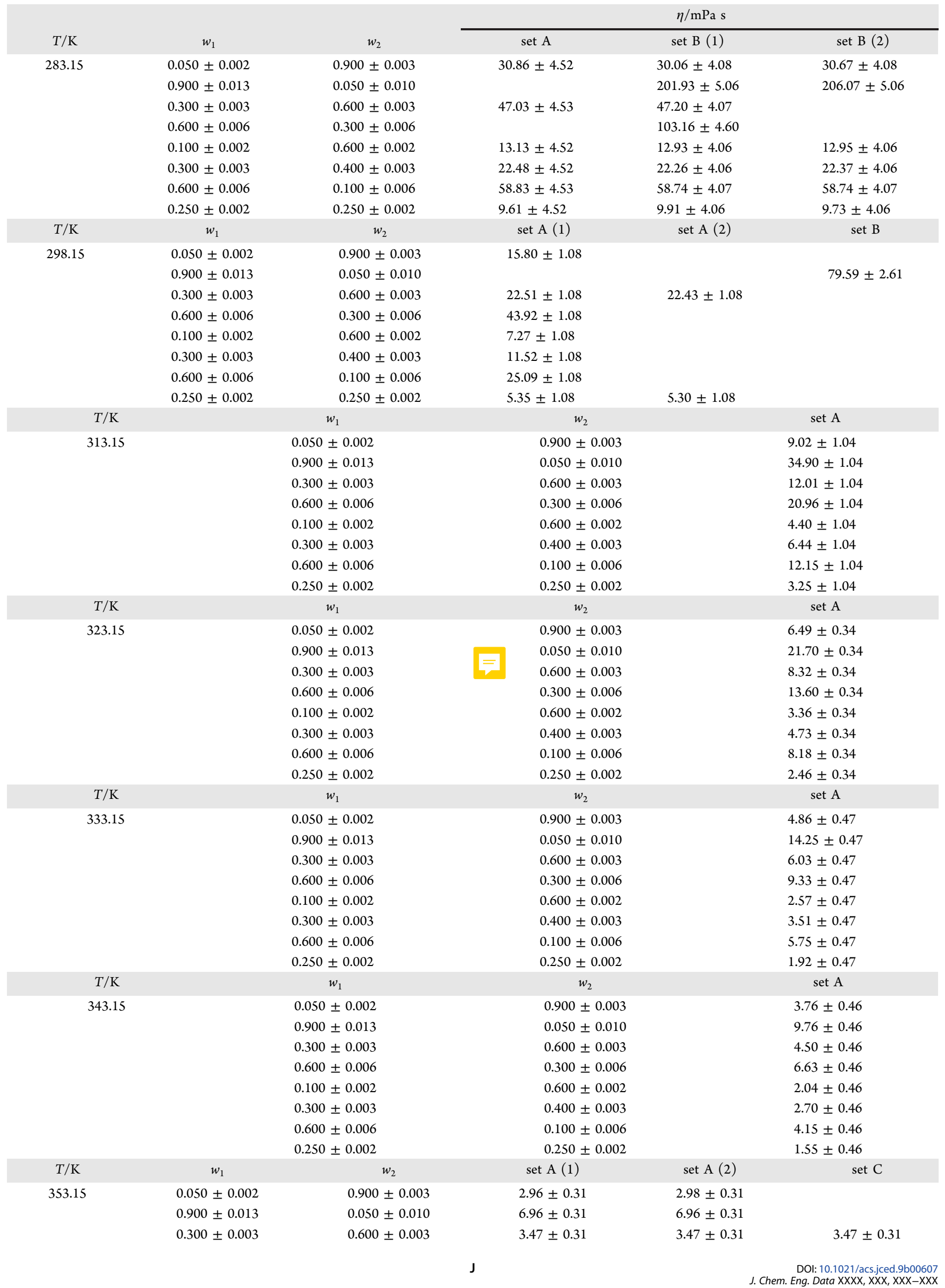


Table 10. continued

$\begin{array}{cccccc}T / K & w_{1} & w_{2} & \text { set A (1) } & \text { set A (2) } & \text { set C } \\ & 0.600 \pm 0.006 & 0.300 \pm 0.006 & 4.89 \pm 0.31 & 4.88 \pm 0.31 \\ 0.100 \pm 0.002 & 0.600 \pm 0.002 & 1.66 \pm 0.31 & 1.66 \pm 0.31 \\ 0.300 \pm 0.003 & 0.400 \pm 0.003 & 2.12 \pm 0.31 & 2.13 \pm 0.31 & \\ & 0.600 \pm 0.006 & 0.100 \pm 0.006 & 3.10 \pm 0.31 & 3.13 \pm 0.31 & 1.26 \pm 0.31 \\ 0.250 \pm 0.002 & 0.250 \pm 0.002 & 1.25 \pm 0.31 & 1.26 \pm 0.31 & \end{array}$

${ }^{a}$ Weight fractions and viscosities are reported with their expanded uncertainties ( 0.95 level of confidence). Expanded uncertainties not included above are $U(T)=0.02 \mathrm{~K}$ and $U(p)=0.0030 \mathrm{MPa}$.

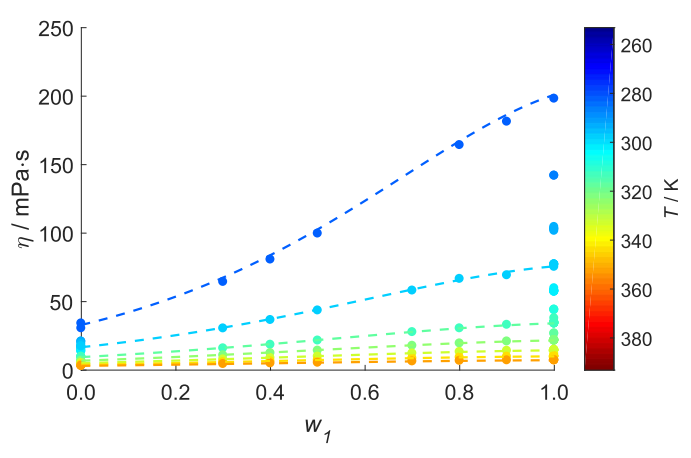

Figure 4. Binary data set of viscosities for $\{$ MDEA (1) + MEG $(2)\}$ and estimations generated by the NRTL-DVIS model. The temperature at which each experimental point (solid circle) was measured is colorcoded by the bar on the right side. The temperatures at which the estimates were made were $283.15 \mathrm{~K}$ (dark-blue dashed line), $298.15 \mathrm{~K}$ (capri-blue dashed line), $313.15 \mathrm{~K}$ (aqua dashed line), $323.15 \mathrm{~K}$ (green dashed line), $333.15 \mathrm{~K}$ (lime-green dashed line), $343.15 \mathrm{~K}$ (yellow dashed line), and $353.15 \mathrm{~K}$ (orange dashed line).

469 models. This variation with temperature makes the fitting of 470 viscosity models more difficult than that of density models, as 471 will be seen briefly.

472 Both the Aspen liquid mixture viscosity model and the NRTL473 DVIS model were tested. One data point from our measure474 ments for the MDEA-MEG binary system was excluded as an 475 outlier $\left(T=283.15 \mathrm{~K}, w_{1}=0.7\right)$. The data fitting parameters and 476 results are shown in Tables 12 and 13 for the Aspen model and 477 the NRTL-DVIS model, respectively. Overall, the Aspen liquid 478 mixture viscosity model showed a slightly worse performance 479 than the NRTL-DVIS equation, returning AARD $=4.39 \%$ and $480 \mathrm{MAD}=16.64 \mathrm{mPa}$ s, whereas the latter showed $\mathrm{AARD}=2.97 \%$ 481 and $\mathrm{MAD}=12.62 \mathrm{mPa}$ s. For the Aspen model, these deviations 482 are more noticeable at lower temperature and viscosity ranges, 483 though they are also present at higher temperatures and 484 viscosities. The previously discussed maximum exhibited in the $485 \mathrm{MDEA}-\mathrm{H}_{2} \mathrm{O}$ system toward higher concentrations of MDEA is 486 particularly problematic for the Aspen model to follow (see 487 figures in the Supporting Information). This difficulty in 488 modeling strong nonideal behavior also arises with the NRTL489 DVIS equation but to a much smaller extent. Comparison 490 between the results of the NRTL-DVIS model and the Aspen 491 liquid viscosity model shows that the fitting of the individual 492 binaries returns higher or similar (for the $\mathrm{MEG}-\mathrm{H}_{2} \mathrm{O}$ system) 493 AARDs and MADs than the latter.

494 In Table 13, one can notice that the largest deviation between 495 estimated and experimental data is obtained for the ternary 496 system, which not only can show high viscosity variations but is 497 also subject to the nonidealities of mixing three very distinct 498 components. The absolute relative deviations (ARDs) between 499 measured and estimated values for ternary systems can be 500 observed in Table S2 in the Supporting Information.
Table 11. Parameters and Results for the Fittings of the Vogel Equation

\begin{tabular}{lcc} 
parameter & MDEA & MEG \\
$\hat{A}$ & -4.3997 & -3.8670 \\
$\hat{B}$ & 1302.2 & 1087.1 \\
$\hat{C}$ & 148.94 & 135.50 \\
AARD (\%) & 1.10 & 2.47 \\
MAD (mPa s) & 3.76 & 2.46 \\
\hline
\end{tabular}

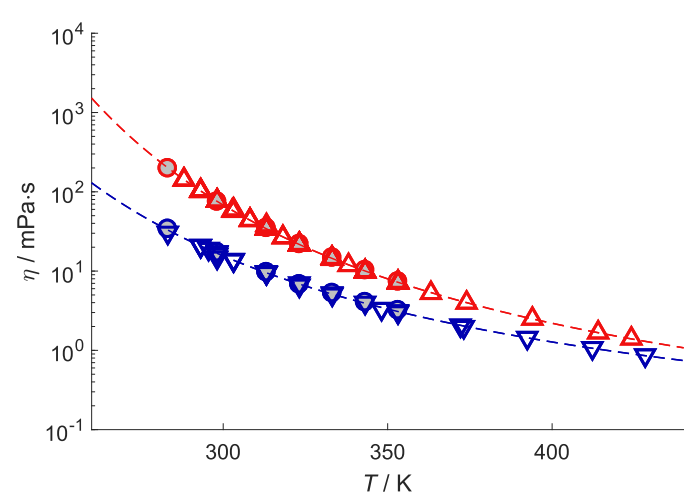

Figure 5. Experimental single-component viscosity of MDEA both obtained in the literature (red open triangle up) and as produced in this work (red $\bigcirc$ filled in gray) and of MEG both obtained in the literature (blue open triangle up) and as produced in this work (blue circle filled in gray), and corresponding estimations with the Vogel equation for MDEA (red dashed line) and MEG (blue dashed line).

Figure 6a,b shows the parity plots between experimental and 501 predicted viscosity data. These figures show that the maximum 502 deviations incurred by the NRTL-DVIS model are on the order 503 of $20 \%$, though the vast majority of these are within $10 \%$. The 504 largest deviations are obtained for the MDEA-water binary 505 system (green asterisks) and the MDEA-MEG- $\mathrm{H}_{2} \mathrm{O}$ ternary 506 system (purple open diamond). These are the conditions under 507 which the widest span of viscosities is observed, which could be 508 the main reason for the fitting difficulties encountered. Figure $6 \mathrm{~b} 509$ suggests that there is no significant trend between the deviations 510 and the temperature, whereas Figure 6a shows that the model 511 may underestimate the viscosities of binary MDEA-water sys- 512 tems and ternary systems at somewhat higher viscosities (noticed 513 by the scatter of green asterisk and purple open diamond above 514 the zero line).

3.3. Excess Properties. To further understand the molec- 516 ular interactions of the system MDEA-MEG- $\mathrm{H}_{2} \mathrm{O}$, we calcu- 517 lated the excess molar volume $v^{\mathrm{E}}$ and viscosity deviations $\Delta \eta$ of 518 the mixtures from the experimental results. For the calculation of 519 excess molar volume $v^{\mathrm{E}}$, we used eq 4 . The calculated excess 520 molar volumes and their uncertainties are shown in Table 14521 and Figure 7 for MDEA-MEG and in Table 15 for MDEA- 522 $\mathrm{MEG}-\mathrm{H}_{2} \mathrm{O}$. 
Table 12. Parameters and Results for the Aspen Liquid Mixture Viscosity Model Fitted for the Global Data Set

\begin{tabular}{|c|c|c|c|c|c|c|}
\hline \multicolumn{7}{|c|}{$\begin{array}{l}\text { Parameters of the Aspen Liquid Mixture Viscosity Model } \\
\qquad(1=\text { MDEA, } 2=\text { MEG, } 3=\text { Water })\end{array}$} \\
\hline$\hat{a}_{12}$ & 2.59783 & $\hat{a}_{13} \quad-$ & -1.37707 & $\hat{a}_{23}$ & \multicolumn{2}{|c|}{0.02792} \\
\hline$\hat{b}_{12}$ & -0.42333 & $\hat{b}_{13}$ & 0.53470 & $\hat{b}_{23}$ & \multicolumn{2}{|c|}{-0.16100} \\
\hline$\hat{c}_{12}$ & 2.74959 & $\hat{c}_{13}$ & -0.10402 & $\hat{c}_{23}$ & \multicolumn{2}{|c|}{0.24937} \\
\hline$\hat{d}_{12}$ & 8385 & $\hat{d}_{13} \quad-$ & -0.32799 & $\hat{d}_{23}$ & \multicolumn{2}{|c|}{0.10408} \\
\hline \multicolumn{7}{|c|}{ Fitting Results in Terms of Binary Data Sets } \\
\hline \multicolumn{2}{|c|}{ MDEA-MEG } & \multicolumn{2}{|c|}{ MDEA-water } & \multicolumn{3}{|c|}{ MEG-water } \\
\hline AARD (\%) & 2.41 & AARD (\%) & 6.55 & AARD & & 2.22 \\
\hline $\mathrm{MAD}$ (mPa s) & 6.77 & $\mathrm{MAD}(\mathrm{mPa} \mathrm{s})$ & 16.64 & MAD & Pa s) & 2.28 \\
\hline \multicolumn{7}{|c|}{ Fitting Results in Terms of the Global Data Set } \\
\hline \multicolumn{4}{|c|}{ AARD ( $\%)$} & \multicolumn{3}{|c|}{4.39} \\
\hline \multicolumn{4}{|c|}{$\operatorname{MAD}(\mathrm{mPa} \mathrm{s})$} & \multicolumn{3}{|c|}{16.64} \\
\hline
\end{tabular}

\section{Table 13. Parameters and Results for the NRTL-DVIS} Equation Fitted for the Global Data Set

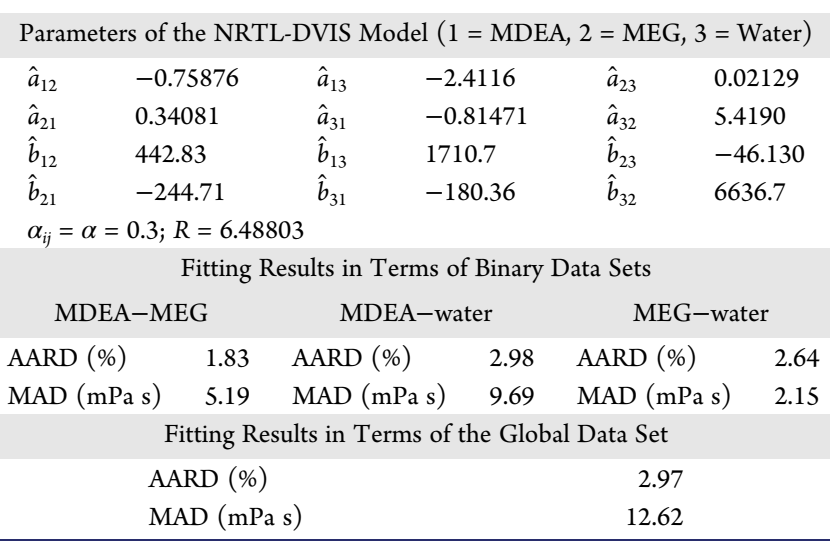

524 For the binary system, excess molar volumes are negative in 525 the whole range of compositions and temperatures studied in 526 this work. Volume reduction upon mixing indicates the presence 527 of charge-transfer and complex-forming interactions between 528 MDEA and MEG, whereas it can also be the result of structural 529 effects such as interstitial accommodation. ${ }^{46,62}$ Both MDEA and 530 MEG are polar molecules; therefore, dipole-dipole interactions 531 should be present between the partial negative charge of one 532 molecule and the partial positive charge of another molecule. 533 Additionally, autoprotolysis of MEG is reported in the 534 literature $^{63,64}$ in the presence of MDEA, implying the breakage of the hydrogen bonding as a MEG molecule is losing its proton. 535 In this case, dipole-ion forces between MDEA, which acts as an 536 electron donor, and the cations formed from MEG autoprotol- 537 ysis would appear. A minimum seems to occur between $x_{1}=0.4538$ and $0.5\left(w_{1}=0.82\right.$ and $\left.w_{2}=0.87\right)$, indicating that these attractive 539 intermolecular forces are the strongest when the molar ratio 540 between MDEA and MEG is close to 1:1.

541

As far as the temperature effect is concerned, Figure 7 shows 542 that the deviations from ideality become smaller when the 543 temperature increases. This is expected and can be explained by 544 the increase of the kinetic energy and weakening of the inter- 545 molecular forces at higher temperatures. In some cases, the calcu- 546 lated excess volumes at different temperatures overlap. However, a 547 closer look at the uncertainties listed in Table 14 reveals that the 548 observed overlaps lie within the uncertainty. Details about the 549 uncertainty analysis of the excess molar volumes can be found in 550 the Supporting Information.

551

The excess molar volumes for the ternary system are also 552 negative, as one could speculate given the negative deviations 553 observed for the binary subsystems. Negative excess volumes 554 have been reported for $\mathrm{MEG}-\mathrm{H}_{2} \mathrm{O}$ by several research- 555 $\mathrm{ers}^{23,25,26}$ with the exception of Yang et al. ${ }^{24}$ who reported 556 positive $v^{\mathrm{E}}$ at $T=313.15-353.15 \mathrm{~K}$ and $w_{1}=0.1$ and 0.2 .557 However, one would expect that the miscibility of the mixture 558 and the known affinity of MEG for water would lead to negative 559 excess molar volumes. As mentioned earlier, the excess volume is 560 a contribution of both intermolecular forces and structural 561 effects. For the MEG- $\mathrm{H}_{2} \mathrm{O}$ system, the dominating attractive 562 intermolecular forces due to the polarity of the molecules 563 contribute to negative $v^{\mathrm{E}}$. In addition, the structure of the water 564 molecule has cavities due to its hydrogen bonds; therefore, it is 565 expected that these empty spaces will be filled partially by other 566 molecules, such as MEG and MDEA, leading also to negative 567 excess volumes. ${ }^{61,65,66}$ Negative deviations from ideality have 568 also been reported for the MDEA- $\mathrm{H}_{2} \mathrm{O}$ system. ${ }^{10,14}$ The MDEA 569 protonation reaction with water is known in the literature, ${ }^{1} 570$ resulting in the formation of strong hydrogen bonds in the 571 mixture. Therefore, higher compactness is expected for the 572 MDEA- $\mathrm{H}_{2} \mathrm{O}$ system in comparison with $\mathrm{MEG}-\mathrm{H}_{2} \mathrm{O}$ due to its 573 strong hydrogen bonding. This is confirmed by the magnitude of 574 their excess molar volumes; at $313.15 \mathrm{~K}$, for example, the 575 minimum $v^{\mathrm{E}}$ is ca. $-1.2 \mathrm{~cm}^{3} \mathrm{~mol}^{-1}$ for MDEA- $\mathrm{H}_{2} \mathrm{O}$ and 576 ca. $-0.3 \mathrm{~cm}^{3} \mathrm{~mol}^{-1}$ for MEG- $\mathrm{H}_{2} \mathrm{O}$. The extreme minimum of 577 $-1.2 \mathrm{~cm}^{3} \mathrm{~mol}^{-1}$ appears at the amine mole fraction close to $x_{1}=578$ $0.3\left(w_{1}=0.75\right)$, which is reflected in the previously mentioned 579

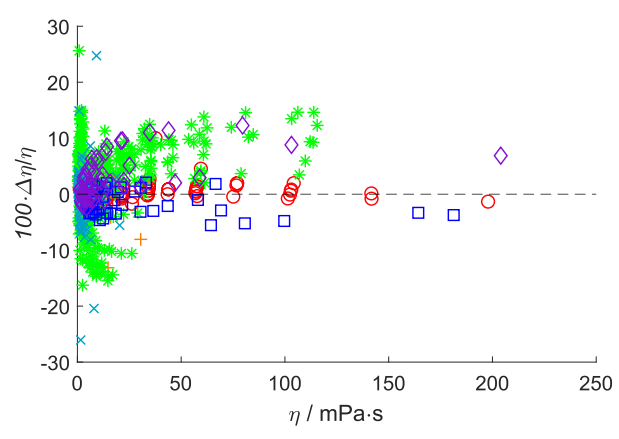

(a)

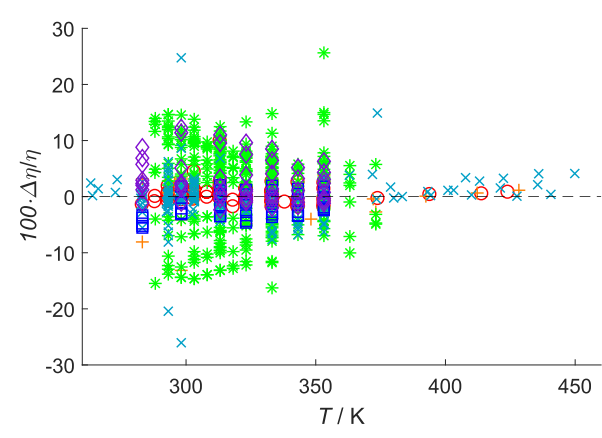

(b)

Figure 6. Deviations in terms of differences between experimental and estimated viscosities divided by experimental viscosities regarding estimations made with the NRTL-DVIS model, and how they vary with the experimental viscosities themselves (a) and with temperature (b). The data sets are distributed in terms of pure MDEA data (red open circle), pure MEG data (orange plus), binary MDEA-water data (green asterisk), binary MEGwater data (cyan cross), binary MDEA-MEG data (blue open square), and ternary data (purple open diamond). 
Table 14. Excess Molar Volumes $v^{\mathrm{E}} / \mathrm{cm}^{3} \operatorname{mol}^{-1}$ for $\{$ MDEA (1) + MEG (2) $\}$ as a Function of Weight Fraction $w$ and Temperature $T$ at Pressure $p=0.1020 \mathrm{MPa}^{a}$

\begin{tabular}{|c|c|c|c|c|}
\hline \multirow[b]{2}{*}{$w_{1}$} & \multicolumn{4}{|c|}{$v^{\mathrm{E}} / \mathrm{cm}^{3} \mathrm{~mol}^{-1}$} \\
\hline & $T=283.15 \mathrm{~K}$ & $T=\sqrt{98} 15 \mathrm{~K}$ & $T=313.15 \mathrm{~K}$ & $T=323.15 \mathrm{~K}$ \\
\hline 0.000 & 0.000 & 0.000 & 0.000 & 0.000 \\
\hline $0.300 \pm 0.003$ & $-0.267 \pm 0.007$ & $-0.247 \pm 0.008$ & $-0.255 \pm 0.009$ & $-0.268 \pm 0.006$ \\
\hline $0.400 \pm 0.003$ & $-0.326 \pm 0.008$ & $-0.319 \pm 0.008$ & $-0.326 \pm 0.008$ & $-0.335 \pm 0.006$ \\
\hline $0.500 \pm 0.004$ & $-0.367 \pm 0.009$ & $-0.357 \pm 0.009$ & $-0.363 \pm 0.009$ & $-0.374 \pm 0.007$ \\
\hline $0.700 \pm 0.006$ & $-0.386 \pm 0.012$ & $-0.368 \pm 0.011$ & $-0.368 \pm 0.011$ & $-0.373 \pm 0.010$ \\
\hline $0.800 \pm 0.008$ & $-0.336 \pm 0.014$ & $-0.307 \pm 0.013$ & $-0.307 \pm 0.012$ & $-0.306 \pm 0.012$ \\
\hline $0.900 \pm 0.009$ & $-0.241 \pm 0.018$ & $-0.192 \pm 0.018$ & $-0.187 \pm 0.017$ & $-0.182 \pm 0.017$ \\
\hline $1.000 \pm 0.011$ & 0.000 & 0.000 & 0.000 & 0.000 \\
\hline$w_{1}$ & \multicolumn{2}{|c|}{$T=333.15 \mathrm{~K}$} & $T=343.15 \mathrm{~K}$ & $T=353.15 \mathrm{~K}$ \\
\hline 0.000 & \multicolumn{2}{|c|}{0.000} & 0.000 & 0.000 \\
\hline $0.300 \pm 0.003$ & \multicolumn{2}{|c|}{$-0.246 \pm 0.004$} & $-0.237 \pm 0.004$ & $-0.230 \pm 0.004$ \\
\hline $0.400 \pm 0.003$ & \multicolumn{2}{|c|}{$-0.307 \pm 0.004$} & $-0.308 \pm 0.004$ & $-0.295 \pm 0.004$ \\
\hline $0.500 \pm 0.004$ & \multicolumn{2}{|c|}{$-0.351 \pm 0.006$} & $-0.341 \pm 0.006$ & $-0.328 \pm 0.006$ \\
\hline $0.700 \pm 0.006$ & \multicolumn{2}{|c|}{$-0.354 \pm 0.009$} & $-0.341 \pm 0.009$ & $-0.326 \pm 0.009$ \\
\hline $0.800 \pm 0.008$ & \multicolumn{2}{|c|}{$-0.293 \pm 0.011$} & $-0.281 \pm 0.011$ & $-0.264 \pm 0.010$ \\
\hline $0.900 \pm 0.009$ & \multicolumn{2}{|c|}{$-0.172 \pm 0.016$} & $-0.174 \pm 0.016$ & $-0.155 \pm 0.017$ \\
\hline $1.000 \pm 0.011$ & 0.000 & & 0.000 & 0.000 \\
\hline
\end{tabular}

${ }^{a}$ Weight fractions and excess molar volumes are reported with their expanded uncertainties ( 0.95 level of confidence). Expanded uncertainties not included above are $U(T)=0.02 \mathrm{~K}$ and $U(p)=0.0030 \mathrm{MPa}$.

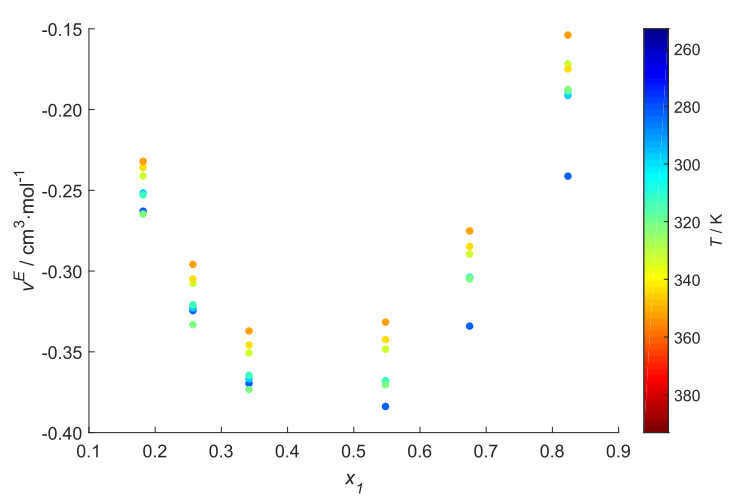

Figure 7. Excess molar volumes for $\{\operatorname{MDEA}(1)+\operatorname{MEG}(2)\}$ as a function of molar fraction and at temperatures $283.15 \mathrm{~K}$ (dark-blue points), $298.15 \mathrm{~K}$ (capri-blue points), $313.15 \mathrm{~K}$ (aqua points), $323.15 \mathrm{~K}$ (green points), $333.15 \mathrm{~K}$ (lime-green points), $343.15 \mathrm{~K}$ (yellow points), and $353.15 \mathrm{~K}$ (orange points).

580 maximum in density, observed at the same mole fraction for $581 \mathrm{MDEA}-\mathrm{H}_{2} \mathrm{O}$ mixtures. Therefore, the negative excess volumes 582 for the ternary system would be the result of mainly the dipole583 ion forces between MDEA and MEG and hydrogen bonds 584 between MDEA and water.

585 As mentioned in Section 2.3, the viscosity deviations were 586 calculated according to eqs 12 and 13. Calculation results and 587 viscosity deviation uncertainties are shown in Table 16 and 588 Figure 8 for MDEA-MEG and in Table 17 for MDEA-MEG$589 \mathrm{H}_{2} \mathrm{O}$.

590 The viscosity deviations for the binary systems $\mathrm{MDEA}-\mathrm{H}_{2} \mathrm{O}$, $591 \mathrm{MEG}-\mathrm{H}_{2} \mathrm{O}$, and MDEA-MEG and the ternary system $592 \mathrm{MDEA}-\mathrm{MEG}-\mathrm{H}_{2} \mathrm{O}$ are positive according to the literature 593 and the additional findings of this work. The positive viscosity 594 deviations from ideality are expected based on the observed 595 negative molar volumes, which indicate the presence of strong 596 molecular interactions between these three chemical com597 pounds, as discussed earlier. The strong hydrogen bonds in $598 \mathrm{MDEA}-\mathrm{H}_{2} \mathrm{O}$ and dipole-ion forces in MDEA-MEG hinder the fluid to flow, leading to a viscosity increase with MDEA concen- 599 tration, as observed in Figures S4 (Supporting Information) and 4, 600 respectively. The former system exhibits a viscosity increase with 601 amine content up to approximately $95 \mathrm{wt} \%\left(x_{1}=0.75\right) .{ }^{14} 602$ It is possible that until this point, the attractive hydrogen bonds 603 predominate over the weaker molecule/ionlike forces. After 604 this point, the abundance of amines or unavailability of water to 605 protonate the amine could lead to a greater contribution from 606 the rest of the forces present in the system.

607

The temperature increase results in lower viscosity deviations 608 due to the weakening of the intermolecular forces. Moreover, it 609 is observed that, unlike in the case of excess volumes of MDEA- 610 MEG where the minima were found at constant amine concen- 611 tration between $x_{1}=0.4$ and 0.5 for all temperatures studied in 612 this work, the viscosity deviation maxima seem to appear at 613 around $x_{1}=0.5$ and shift at higher mole fractions as the 614 temperature decreases. In addition, there is a mismatch between 615 the amine concentration at which the $\min v^{\mathrm{E}}$ and $\max \Delta \eta$ appear. 616 This mismatch has also been observed for the binary MDEA- 617 $\mathrm{H}_{2} \mathrm{O}$. According to Yin et al. ${ }^{14}$ and Sathyanarayana et al., ${ }^{67}$ this 618 behavior can be explained by the effects based on the shape, size, 619 and structure of the molecules, which are able to dominate over 620 the intermolecular effects and even reverse the sign of the 621 viscosity deviation.

The density and viscosity models developed in this work serve 623 as an assessment tool for the successful employment of the 624 binary MDEA-MEG or the ternary MDEA-MEG- $\mathrm{H}_{2} \mathrm{O}$ sys- 625 tems at various temperature conditions. An example is the use of 626 the developed viscosity model to construct viscosity contour 627 plots, such as Figure 9, to identify the viscosity limits for oper- 628 ational reasons in a specific process. To read Figure 9, one can 629 directly find the weight fraction of MEG in the $X$ axis and the 630 weight fraction of MDEA in the $Y$ axis so that the remainder of 631 the mass will be assigned to water. In $X=Y=0$, therefore, what is 632 seen is the viscosity of pure water.

633

If one is concerned with avoiding a certain limiting viscosity 634 when employing a MDEA-MEG- $\mathrm{H}_{2} \mathrm{O}$ solution, for example, 635 $200 \mathrm{mPa}$ s at $278.15 \mathrm{~K}$, Figure 9 shows that systems with more 636 
Table 15. Excess Molar Volumes $v^{\mathrm{E}} / \mathrm{cm}^{3} \mathrm{~mol}^{-1}$ for $\{$ MDEA (1) + MEG (2) + Water (3) $\}$ as a Function of Weight Fraction $w$ and Temperature $T$ at Pressure $p=0.1020 \mathrm{MPa}^{a}$

\begin{tabular}{|c|c|c|c|c|c|}
\hline \multirow[b]{2}{*}{$w_{1}$} & \multirow[b]{2}{*}{$w_{2}$} & \multicolumn{4}{|c|}{$v^{\mathrm{E}} / \mathrm{cm}^{3} \mathrm{~mol}^{-1}$} \\
\hline & & $T=283.15 \mathrm{~K}$ & $T=298.15 \mathrm{~K}$ & $T=313.15 \mathrm{~K}$ & $T=323.15 \mathrm{~K}$ \\
\hline $0.050 \pm 0.002$ & $0.900 \pm 0.003$ & $-0.210 \pm 0.008$ & $-0.181 \pm 0.009$ & $-0.179 \pm 0.006$ & $-0.211 \pm 0.020$ \\
\hline $0.900 \pm 0.013$ & $0.050 \pm 0.010$ & $-0.707 \pm 0.021$ & $-0.670 \pm 0.023$ & $-0.657 \pm 0.019$ & $-0.674 \pm 0.039$ \\
\hline $0.300 \pm 0.003$ & $0.600 \pm 0.003$ & $-0.571 \pm 0.007$ & $-0.533 \pm 0.009$ & $-0.514 \pm 0.005$ & $-0.533 \pm 0.019$ \\
\hline $0.600 \pm 0.006$ & $0.300 \pm 0.006$ & $-0.856 \pm 0.012$ & $-0.815 \pm 0.013$ & $-0.792 \pm 0.010$ & $-0.801 \pm 0.024$ \\
\hline $0.100 \pm 0.002$ & $0.600 \pm 0.002$ & $-0.508 \pm 0.004=$ & $-0.455 \pm 0.005$ & $-0.421 \pm 0.002$ & $-0.407 \pm 0.012$ \\
\hline $0.300 \pm 0.003$ & $0.400 \pm 0.003$ & $-0.724 \pm 0.005$ & $-0.666 \pm 0.006$ & $-0.633 \pm 0.004$ & $-0.613 \pm 0.012$ \\
\hline $0.600 \pm 0.006$ & $0.100 \pm 0.006$ & $-1.089 \pm 0.007$ & $-1.026 \pm 0.008$ & $-0.985 \pm 0.005$ & $-0.969 \pm 0.015$ \\
\hline $0.250 \pm 0.002$ & $0.250 \pm 0.002$ & $-0.570 \pm 0.003$ & $-0.512 \pm 0.004$ & $-0.489 \pm 0.003$ & $-0.466 \pm 0.009$ \\
\hline$w_{1}$ & $w_{2}$ & \multicolumn{2}{|c|}{$T=333.15 \mathrm{~K}$} & $T=343.15 \mathrm{~K}$ & $T=353.15 \mathrm{~K}$ \\
\hline $0.050 \pm 0.002$ & $0.900 \pm 0.003$ & \multicolumn{2}{|c|}{$-0.179 \pm 0.024$} & $-0.180 \pm 0.024$ & $-0.191 \pm 0.032$ \\
\hline $0.900 \pm 0.013$ & $0.050 \pm 0.010$ & \multicolumn{2}{|c|}{$-0.667 \pm 0.046$} & $-0.659 \pm 0.045$ & $-0.648 \pm 0.059$ \\
\hline $0.300 \pm 0.003$ & $0.600 \pm 0.003$ & \multicolumn{2}{|c|}{$-0.504 \pm 0.022$} & $-0.500 \pm 0.022$ & $-0.497 \pm 0.029$ \\
\hline $0.600 \pm 0.006$ & $0.300 \pm 0.006$ & \multicolumn{2}{|c|}{$-0.783 \pm 0.028$} & $-0.765 \pm 0.027$ & $-0.751 \pm 0.036$ \\
\hline $0.100 \pm 0.002$ & $0.600 \pm 0.002$ & \multicolumn{2}{|c|}{$-0.395 \pm 0.014$} & $-0.379 \pm 0.014$ & $-0.372 \pm 0.018$ \\
\hline $0.300 \pm 0.003$ & $0.400 \pm 0.003$ & \multicolumn{2}{|c|}{$-0.608 \pm 0.015$} & $-0.590 \pm 0.014$ & $-0.573 \pm 0.019$ \\
\hline $0.600 \pm 0.006$ & $0.100 \pm 0.006$ & \multicolumn{2}{|c|}{$-0.940 \pm 0.018$} & $-0.913 \pm 0.018$ & $-0.887 \pm 0.024$ \\
\hline $0.250 \pm 0.002$ & $0.250 \pm 0.002$ & \multicolumn{2}{|c|}{$-0.466 \pm 0.011$} & $-0.456 \pm 0.011$ & $-0.441 \pm 0.014$ \\
\hline
\end{tabular}

${ }^{a}$ Weight fractions and excess molar volumes are reported with their expanded uncertainties ( 0.95 level of confidence). Expanded uncertainties not included above are $U(T)=0.02 \mathrm{~K}$ and $U(p)=0.0030 \mathrm{MPa}$.

Table 16. Viscosity Deviations $\Delta \eta / \mathrm{mPa}$ s for $\{$ MDEA (1) + MEG (2) $\}$ as a Function of Weight Fraction $w$ and Temperature $T$ at Pressure $p=0.1020 \mathrm{MPa}^{a}$

\begin{tabular}{|c|c|c|c|c|}
\hline \multirow[b]{2}{*}{$w_{1}$} & \multicolumn{4}{|c|}{$\Delta \eta / \mathrm{mPa} \mathrm{s}$} \\
\hline & $T=283.15 \mathrm{~K}$ & $T=298.15 \mathrm{~K}$ & $T=313.15 \mathrm{~K}$ & $T=323.15 \mathrm{~K}$ \\
\hline 0.000 & 0.00 & 0.00 & 0.00 & 0.00 \\
\hline $0.300 \pm 0.003$ & $17.34 \pm 4.01$ & $7.82 \pm 1.36$ & $3.63 \pm 0.82$ & $2.36 \pm 0.50$ \\
\hline $0.400 \pm 0.003$ & $27.03 \pm 4.06$ & $11.32 \pm 1.37$ & $5.02 \pm 0.97$ & $3.22 \pm 0.50$ \\
\hline $0.500 \pm 0.004$ & $37.45 \pm 5.09$ & $14.97 \pm 1.68$ & $6.54 \pm 0.83$ & $4.04 \pm 0.50$ \\
\hline $0.700 \pm 0.006$ & & $19.30 \pm 2.87$ & $8.10 \pm 0.91$ & $4.80 \pm 0.51$ \\
\hline $0.800 \pm 0.008$ & $52.26 \pm 6.24$ & $19.83 \pm 3.02$ & $7.38 \pm 1.03$ & $4.45 \pm 0.54$ \\
\hline $0.900 \pm 0.009$ & $35.98 \pm 8.99$ & $11.06 \pm 3.69$ & $5.10 \pm 1.13$ & $3.04 \pm 0.69$ \\
\hline $1.000 \pm 0.011$ & 0.00 & 0.00 & 0.00 & 0.00 \\
\hline$w_{1}$ & \multicolumn{2}{|c|}{$T=33315 \mathrm{~K}$} & $T=343.15 \mathrm{~K}$ & $T=353.15 \mathrm{~K}$ \\
\hline 0.000 & \multicolumn{2}{|c|}{0.00} & 0.00 & 0.00 \\
\hline $0.300 \pm 0.003$ & \multicolumn{2}{|c|}{$1.44 \pm 0.43$} & $0.94 \pm 0.64$ & $0.69 \pm 0.28$ \\
\hline $0.400 \pm 0.003$ & \multicolumn{2}{|c|}{$1.93 \pm 0.57$} & $1.29 \pm 0.64$ & $0.91 \pm 0.37$ \\
\hline $0.500 \pm 0.004$ & \multicolumn{2}{|c|}{$2.42 \pm 0.57$} & $1.59 \pm 0.63$ & $1.09 \pm 0.37$ \\
\hline $0.700 \pm 0.006$ & \multicolumn{2}{|c|}{$2.86 \pm 0.56$} & $1.85 \pm 0.61$ & $1.24 \pm 0.36$ \\
\hline $0.800 \pm 0.008$ & \multicolumn{2}{|c|}{$2.65 \pm 0.57$} & $1.65 \pm 0.61$ & $1.11 \pm 0.35$ \\
\hline $0.900 \pm 0.009$ & \multicolumn{2}{|c|}{$1.71 \pm 0.49$} & $1.07 \pm 0.64$ & $0.74 \pm 0.26$ \\
\hline $1.000 \pm 0.011$ & \multicolumn{2}{|c|}{0.00} & 0.00 & 0.00 \\
\hline
\end{tabular}

${ }^{a}$ Weight fractions and viscosity deviations are reported with their expanded uncertainties ( 0.95 level of confidence). Expanded uncertainties not included above are $U(T)=0.02 \mathrm{~K}$ and $U(p)=0.0030 \mathrm{MPa}$.

637 than 80 wt \% MDEA approach or even exceed the viscosity 638 specification and are not suitable. Alternatively, if one wants to 639 find the viscosity of an 80 wt \% MDEA-15 wt \% MEG-5 wt \% $640 \mathrm{H}_{2} \mathrm{O}$, one should read 80 in the $Y$ axis and 15 in the $X$ axis and 641 find their viscosity at the point their imaginary lines intersect. 642 At $288.15 \mathrm{~K}$ however, any composition for the ternary system 643 respects the viscosity limit of $200 \mathrm{mPa}$.

644 In addition, similar to the observations made for the aqueous 645 MDEA exhibiting the maximum viscosity at approximately 95 wt \% 646 MDEA, experimentally determined viscosities for the ternary 647 system 90 wt \% MDEA-5 wt \% MEG-5 wt \% $\mathrm{H}_{2} \mathrm{O}$ are also 648 higher than those for the pure amine at temperatures lower than
313.15 K. Therefore, the addition of water as a means of reduc- 649 ing the viscosity, for example, to reach the viscosity specifications, 650 should be used cautiously and after advising Figure 9. Naturally, 651 knowing that the NRTL-DVIS model is underestimating the 652 viscosities of MDEA-rich solutions, some additional attention 653 should be paid. Overall, the models have been checked at tem- 654 peratures outside the temperature range they were developed at, 655 and it is observed that they are able to capture the trends for both 656 density and viscosity. However, since the model is not validated 657 outside the 283.15-353.15 K range as there are no experimental 658 data available for the systems MDEA-MEG and MDEA- 659 MEG $-\mathrm{H}_{2} \mathrm{O}$, any extrapolation must be performed with caution. 660 


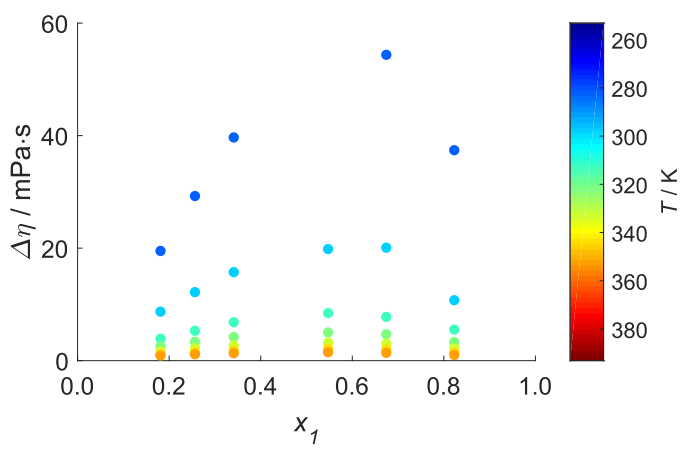

Figure 8. Viscosity deviations $\Delta \eta$ for $\{$ MDEA (1) + MEG (2) $\}$ as a function of molar fraction and at temperatures $283.15 \mathrm{~K}$ (dark-blue points), $298.15 \mathrm{~K}$ (capri-blue points), $313.15 \mathrm{~K}$ (aqua points), $323.15 \mathrm{~K}$ (green points), $333.15 \mathrm{~K}$ (lime-green points), $343.15 \mathrm{~K}$ (yellow points), and $353.15 \mathrm{~K}$ (orange points).

\section{CONCLUSIONS}

New density and viscosity data were obtained for the systems 661 MDEA-MEG and MDEA-MEG- $\mathrm{H}_{2} \mathrm{O}$ at temperature $T=662$ 283.15-353.15 $\mathrm{K}$ due to the potential application of the mixture 663 for the combined $\mathrm{H}_{2} \mathrm{~S}$ removal and hydrate control in natural gas 664 processing. The measurements showed good repeatability and 665 reproducibility, and the excess molar volume and viscosity 666 deviations upon mixing were calculated. Negative excess molar 667 volumes and positive viscosity deviations indicated the strong 668 nonideality of the mixtures at the studied compositions and 669 temperatures. Density has been modeled successfully using the 670 NRTL-DVOL model, exhibiting AARDs lower than 0.4\%. The 671 Aspen liquid mixture viscosity model and the NRTL-DVIS 672 model were employed for the estimation of the viscosity data 673 obtained in this work. They both perform satisfactorily, with 674 the latter yielding slightly better results. The results for the 675

Table 17. Viscosity Deviations $\Delta \eta / \mathrm{mPa}$ s for $\{$ MDEA (1) + MEG (2) + Water (3) $\}$ as a Function of Weight Fraction $w$ and Temperature $T$ at Pressure $p=0.1020 \mathrm{MPa}^{a}$

\begin{tabular}{|c|c|c|c|c|c|}
\hline \multirow[b]{2}{*}{$w_{1}$} & \multirow[b]{2}{*}{$w_{2}$} & \multicolumn{4}{|c|}{$\Delta \eta / \mathrm{mPa} \mathrm{s}$} \\
\hline & & $T=283.15 \mathrm{~K}$ & $T=298.15 \mathrm{~K}$ & $T=313.15 \mathrm{~K}$ & $T=323.15 \mathrm{~K}$ \\
\hline $0.050 \pm 0.002$ & $0.900 \pm 0.003$ & $9.13 \pm 2.75$ & $4.50 \pm 1.16$ & $2.43 \pm 1.10$ & $1.73 \pm 0.40$ \\
\hline $0.900 \pm 0.013$ & $0.050 \pm 0.010$ & $154.38 \pm 6.08$ & $57.22 \pm 3.18$ & $12.53 \pm 2.10$ & $13.63 \pm 0.59$ \\
\hline $0.300 \pm 0.003$ & $0.600 \pm 0.003$ & $31.30 \pm 3.11$ & $14.00 \pm 0.79$ & $3.54 \pm 1.06$ & $4.62 \pm 0.36$ \\
\hline $0.600 \pm 0.006$ & $0.300 \pm 0.006$ & $84.45 \pm 4.11$ & $34.27 \pm 1.11$ & $11.31 \pm 1.07$ & $9.53 \pm 0.35$ \\
\hline $0.100 \pm 0.002$ & $0.600 \pm 0.002$ & $8.10 \pm 2.44$ & $4.29 \pm 1.08$ & $1.42 \pm 1.04$ & $1.82 \pm 0.34$ \\
\hline $0.300 \pm 0.003$ & $0.400 \pm 0.003$ & $17.48 \pm 2.44$ & $8.57 \pm 1.08$ & $3.49 \pm 1.04$ & $3.21 \pm 0.34$ \\
\hline $0.600 \pm 0.006$ & $0.100 \pm 0.006$ & $53.89 \pm 2.44$ & $22.20 \pm 1.08$ & $9.26 \pm 1.04$ & $6.69 \pm 0.34$ \\
\hline $0.250 \pm 0.002$ & $0.250 \pm 0.002$ & $7.10 \pm 2.44$ & $3.63 \pm 0.76$ & $1.55 \pm 1.04$ & $1.50 \pm 0.34$ \\
\hline$w_{1}$ & \multicolumn{3}{|c|}{$T=333.15 \mathrm{~K}$} & $T=343.15 \mathrm{~K}$ & $T=353.15 \mathrm{~K}$ \\
\hline $0.050 \pm 0.002$ & $0.900 \pm 0.003$ & \multicolumn{2}{|c|}{$1.15 \pm 0.51$} & $0.86 \pm 0.53$ & $0.65 \pm 0.26$ \\
\hline $0.900 \pm 0.013$ & $0.050 \pm 0.010$ & \multicolumn{2}{|c|}{$8.47 \pm 0.57$} & $5.49 \pm 0.52$ & $3.71 \pm 0.26$ \\
\hline $0.300 \pm 0.003$ & $0.600 \pm 0.003$ & \multicolumn{2}{|c|}{$3.17 \pm 0.48$} & $2.25 \pm 0.48$ & $1.66 \pm 0.19$ \\
\hline $0.600 \pm 0.006$ & $0.300 \pm 0.006$ & \multicolumn{2}{|c|}{$6.25 \pm 0.48$} & $4.24 \pm 0.47$ & $2.98 \pm 0.22$ \\
\hline $0.100 \pm 0.002$ & $0.600 \pm 0.002$ & \multicolumn{2}{|c|}{$1.34 \pm 0.47$} & $1.03 \pm 0.46$ & $0.81 \pm 0.22$ \\
\hline $0.300 \pm 0.003$ & $0.400 \pm 0.003$ & \multicolumn{2}{|c|}{$2.30 \pm 0.47$} & $1.71 \pm 0.46$ & $1.29 \pm 0.22$ \\
\hline $0.600 \pm 0.006$ & $0.100 \pm 0.006$ & \multicolumn{2}{|c|}{$4.59 \pm 0.47$} & $3.20 \pm 0.46$ & $2.32 \pm 0.22$ \\
\hline $0.250 \pm 0.002$ & $0.250 \pm 0.002$ & \multicolumn{2}{|c|}{$1.15 \pm 0.47$} & $0.90 \pm 0.46$ & $0.70 \pm 0.18$ \\
\hline
\end{tabular}

${ }^{a}$ Weight fractions and viscosity deviations are reported with their expanded uncertainties ( 0.95 level of confidence). Expanded uncertainties not included above are $U(T)=0.02 \mathrm{~K}$ and $U(p)=0.0030 \mathrm{MPa}$.
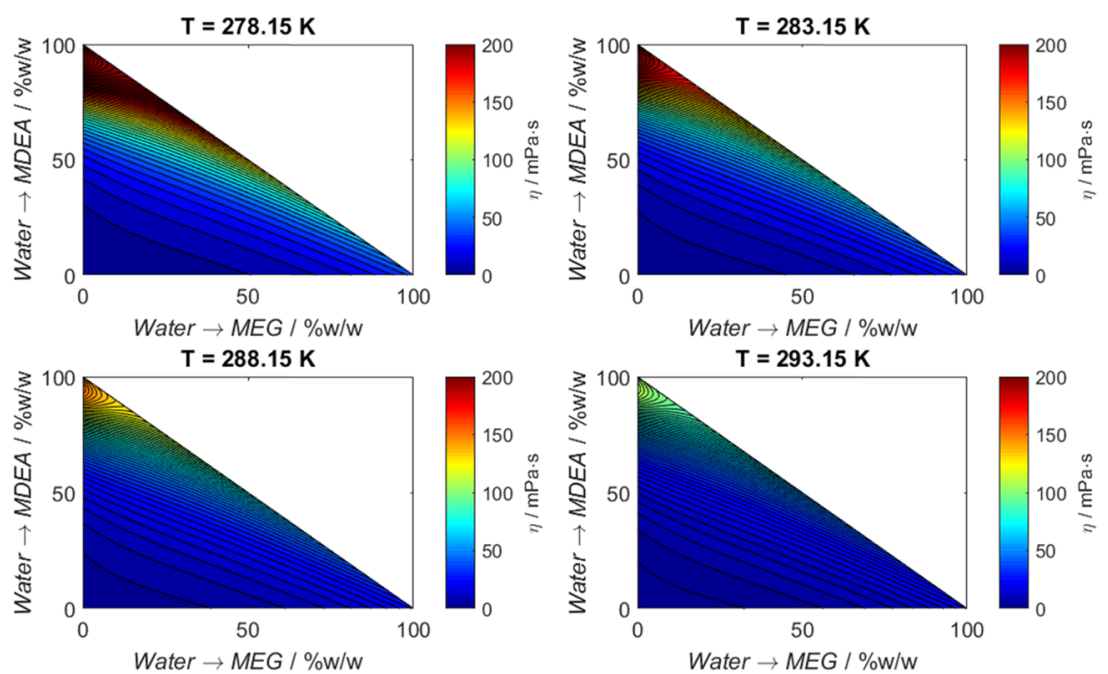

Figure 9. Viscosity plots for MDEA-MEG-water ternary mixtures at four different temperatures (278.15, 283.15, 288.15, and 293.15 K). The viscosity values are color-coded by the bar on the right side. 
676 parametrization of the NRTL-DVIS model showed AARDs 677 lower than $3 \%$.

\section{ASSOCIATED CONTENT}

\section{S Supporting Information}

680 The Supporting Information is available free of charge on the 681 ACS Publications website at DOI: 10.1021/acs.jced.9b00607.

682 Experimental and predicted viscosities with the NRTL683 DVOL model; experimental and predicted viscosities 684 with the NRTL-DVIS model; experimental and predicted 685 viscosities with the Aspen liquid mixture viscosity model; 686 and-uncertainty analysis (PDF)

\section{AUTHOR INFORMATION}

\section{Corresponding Author}

689 *E-mail: hanna.knuutila@ntnu.no.

690 ORCID $\odot$

691 Hanna K. Knuutila: 0000-0003-2057-1743

\section{Author Contributions}

693 The manuscript was written through contributions of all 694 authors. All authors have given approval to the final version of 695 the manuscript.

\section{Funding}

697 This work was carried out as a part of Subsea Production and 698 Processing (SUBPRO), a Research-based Innovation Centre 699 within Subsea Production and Processing. The authors 700 gratefully acknowledge the financial support from SUBPRO, 701 which is financed by the Norwegian University of Science and 702 Technology (NTNU), major industry partners, and the 703 Research Council of Norway (RCN) under project number 704 237893. The authors also acknowledge the financial support 705 from the Faculty of Natural Sciences of NTNU.

\section{Notes}

707 The authors declare no competing financial interest.

\section{NOMENCLATURE}

\section{Symbols}

$710 a_{i j}, b_{i j}, c_{i j}, d_{i j}, G_{i j}, k_{i j}$, binary parameters for the density and $711 l_{i j}, \alpha_{i j}, \tau_{i j} \quad$ viscosity models (DVOL, DVIS, and $712 A_{i}, B_{i}, C_{i}$

$713 \mathrm{MW}_{i}$

$714 \mathrm{NC}$

$715 \mathrm{NP}$

$716 p$

$717 p_{\mathrm{C}, i}$

$718 p_{\mathrm{r}, i}$

$719 R$

$720 \mathrm{~T}$

$721 T_{\mathrm{C}, i}$

$722 T_{\mathrm{r}, i}$

$723 v_{i}$

$724 v^{\mathrm{E}}$

$725 Z_{\mathrm{RA}, i}$

$726 w_{i}$

$728 x_{i}$ Aspen liquid mixture viscosity models) single-component parameters for the individual density and viscosity models (Rackett and Vogel)

molar weight of component $i$ (kg mol)

number of components

number of points

pressure $(\mathrm{Pa})$

critical pressure of component $i(\mathrm{~Pa})$

reduced pressure of component $i$

ideal gas constant $\left(\mathrm{m}^{3} \mathrm{~Pa} \mathrm{~K}^{-1} \mathrm{~mol}^{-1}\right)$

temperature $(\mathrm{K})$

critical temperature of component $i(\mathrm{~K})$

reduced temperature of component $i$

molar volume of component $i$ $\left(\mathrm{m}^{3} \mathrm{~mol}^{-1}\right)$

excess molar volume of a mixture $\left(\mathrm{m}^{3} \mathrm{~mol}^{-1}\right)$ compressibility factor of component $i$ as obtained by the Rackett equation mass fraction of component $i$ in a mixture molar fraction of component $i$ in a mixture

\section{Greek Letters}

$\Delta \eta \quad$ viscosity deviation ( $\mathrm{mPa} \mathrm{s})$

$\eta \quad$ viscosity ( $\mathrm{mPa} \mathrm{s}$ )

$\eta_{i} \quad$ viscosity of single component $i$ ( $\mathrm{mPa} \mathrm{s}$ )

binary parameter for the Aspen liquid mixture viscosity 733 model (mPa s)

$\eta^{\mathrm{E}} \quad$ excess viscosity ( $\left.\mathrm{mPa} \mathrm{s}\right)$

$\rho$ density $\left(\mathrm{kg} \mathrm{m}^{-3}\right)$

$\rho_{i} \quad$ density of single component $i\left(\mathrm{~kg} \mathrm{~m}^{-3}\right)$

$\varphi_{\mathrm{H}_{2} \mathrm{O}}$ water fluidity $\left(\mathrm{p}^{-1}\right)$ 
795 (17) Pinto, D. D. D.; Johnsen, B.; Awais, M.; Svendsen, H. F.; 796 Knuutila, H. K. Viscosity Measurements and Modeling of Loaded and 797 Unloaded Aqueous Solutions of MDEA, DMEA, DEEA and MAPA. 798 Chem. Eng. Sci. 2017, 171, 340-350.

799 (18) Chowdhury, F. I.; Akhtar, S.; Saleh, M. A. Viscosities and Excess 800 Viscosities of Aqueous Solutions of Some Diethanolamines. J. Mol. Liq. 801 2010, 155, 1-7.

802 (19) Rinker, E. B.; Oelschlager, D. W.; Colussi, A. T.; Henry, K. R.; 803 Sandall, O. C. Viscosity, Density, and Surface Tension of Binary 804 Mixtures of Water and N-Methyldiethanolamine and Water and 805 Diethanolamine and Tertiary Mixtures of These Amines with Water 806 over the Temperature Range 20-100.Degree.C. J. Chem. Eng. Data 807 1994, 39, 392-395.

808 (20) Baek, J.-I.; Yoon, J.-H.; Eum, H.-M. Physical and Thermody809 namic Properties of Aqueous 2-Amino-2-Methyl-1,3-Propanediol 810 Solutions. Int. J. Thermophys. 2000, 21, 1175-1184.

811 (21) Hayduk, W.; Malik, V. K. Density, Viscosity, and Carbon Dioxide 812 Solubility and Diffusivity in Aqueous Ethylene Glycol Solutions. J. 813 Chem. Eng. Data 1971, 16, 143-146.

814 (22) Bohne, D.; Fischer, S.; Obermeier, E. Thermal, Conductivity, 815 Density, Viscosity, and Prandtl-Numbers of Ethylene Glycol-Water 816 Mixtures. Bunsen-Ges. Phys. Chem., Ber. 1984, 88, 739-742.

817 (23) Sun, T.; Teja, A. S. Density, Viscosity, and Thermal Conductivity 818 of Aqueous Ethylene, Diethylene, and Triethylene Glycol Mixtures 819 between $290 \mathrm{~K}$ and $450 \mathrm{~K}$. J. Chem. Eng. Data 2003, 48, 198-202.

820 (24) Yang, C.; Ma, P.; Jing, F.; Tang, D. Excess Molar Volumes, 821 Viscosities, and Heat Capacities for the Mixtures of Ethylene Glycol + 822 Water from $273.15 \mathrm{~K}$ to $353.15 \mathrm{~K}$. J. Chem. Eng. Data 2003, 48, 836823840 .

824 (25) Tsierkezos, N. G.; Molinou, I. E. Thermodynamic Properties of 825 Water + Ethylene Glycol at 283.15, 293.15, 303.15, and 313.15 K. J. 826 Chem. Eng. Data 1998, 43, 989-993.

827 (26) Afzal, W.; Mohammadi, A. H.; Richon, D. Volumetric Properties 828 of Mono-, Di-, Tri-, and Polyethylene Glycol Aqueous Solutions from 829 (273.15 to 363.15) K: Experimental Measurements and Correlations. J. 830 Chem. Eng. Data 2009, 54, 1254-1261.

831 (27) Braun, N. O.; Persson, U. Å.; Karlsson, H. T. Densities and 832 Viscosities of Mono(Ethylene Glycol) + 2-Amino-2-Methyl-1-Prop833 anol + Water. J. Chem. Eng. Data 2001, 46, 805-808.

834 (28) Song, J.-H.; Park, S.-B.; Yoon, J.-H.; Lee, H.; Lee, K.-H. Densities 835 and Viscosities of Monoethanolamine + Ethylene Glycol + Water. J. 836 Chem. Eng. Data 1996, 41, 1152-1154.

837 (29) Li, L.; Zhang, J.; Li, Q.; Guo, B.; Zhao, T.; Sha, F. Density, 838 Viscosity, Surface Tension, and Spectroscopic Properties for Binary 839 System of 1,2-Ethanediamine+diethylene Glycol. Thermochim. Acta 840 2014, 590, 91-99.

841 (30) Zhao, T.; Zhang, J.; Li, L.; Guo, B.; Gao, L.; Wei, X. Excess 842 Properties and Spectroscopic Studies for the Binary System 1,2843 Ethanediamine+polyethylene Glycol 300 at $\mathrm{T}=(293.15,298.15$, 844 303.15, 308.15, 313.15, and 318.15) K. J. Mol. Liq. 2014, 198, 21-29. 845 (31) DiGuilio, R. M.; Lee, R. J.; Schaeffer, S. T.; Brasher, L. L.; Teja, A. 846 S. Densities and Viscosities of the Ethanolamines. J. Chem. Eng. Data 847 1992, 37, 239-242.

848 (32) Álvarez, E.; Gómez-Díaz, D.; La Rubia, M. D.; Navaza, J. M. 849 Densities and Viscosities of Aqueous Ternary Mixtures of 2850 (Methylamino)Ethanol and 2-(Ethylamino)Ethanol with Diethanol851 amine, Triethanolamine, N-Methyldiethanolamine, or 2-Amino-1852 Methyl-1-Propanol from 298.15 to 323.15 K. J. Chem. Eng. Data 853 2006, 51, 955-962.

854 (33) Henni, A.; Maham, Y.; Tontiwachwuthikul, P.; Chakma, A.; 855 Mather, A. E. Densities and Viscosities for Binary Mixtures of N856 Methyldiethanolamine plus Triethylene Glycol Monomethyl Ether 857 from 25 Degrees $C$ to 70 Degrees $C$ and N-Methyldiethanolamine plus 858 Ethanol Mixtures at 40 Degrees C. J. Chem. Eng. Data 2000, 45, 247859253.

860 (34) Haghtalab, A.; Shojaeian, A. Volumetric and Viscometric 861 Behaviour of the Binary Systems of N-Methyldiethanolamine and 862 Diethanolamine with 1-Butyl-3-Methylimidazolium Acetate at Various 863 Temperatures. J. Chem. Thermodyn. 2014, 68, 128-137.
(35) Akbar, M. M.; Murugesan, T. Thermophysical Properties for the 864 Binary Mixtures of 1-Hexyl-3-Methylimidazolium Bis- 865 (Trifluoromethylsulfonyl)Imide [Hmim] [Tf2N]+N-Methyldiethanol- 866 amine (MDEA) at Temperatures (303.15 to 323.15) K. J. Mol. Liq. 867 2012, 169, 95-101.

(36) Tsierkezos, N. G.; Molinou, I. E. Transport Properties of 2:2 869 Symmetrical Electrolytes in (Water+ethylene Glycol) Binary Mixtures 870 at $\mathrm{T}=293.15 \mathrm{~K}$. J. Chem. Thermodyn. 2006, 38, 1422-1431. 871

(37) Jerome, F. S.; Tseng, J. T.; Fan, L. T. Viscosities of Aqueous 872 Glycol Solutions. J. Chem. Eng. Data 1968, 13, 496.

(38) Dunstan, A. E. IV.-The Viscosity of Liquid Mixtures. Part II. J. 874 Chem. Soc., Trans. 1905, 87, 11-17. 875

(39) Rumble, J. CRC Handbook of Chemistry and Physics; CRC Press, 876 2017.

(40) Hartono, A.; Mba, E. O.; Svendsen, H. F. Physical Properties of 878 Partially $\mathrm{CO}_{2}$ Loaded Aqueous Monoethanolamine (MEA). J. Chem. 879 Eng. Data 2014, 59, 1808-1816.

(41) Poli, R.; Kennedy, J.; Blackwell, T. Particle Swarm Optimization. 881 Swarm Intell. 2007, 1, 33-57.

(42) Ghosh, S.; Das, S.; Kundu, D.; Suresh, K.; Abraham, A. Inter- 883 Particle Communication and Search-Dynamics of Lbest Particle Swarm 884 Optimizers: An Analysis. Inf. Sci. 2012, 182, 156-168. 885

(43) Evjen, S.; Wanderley, R.; Fiksdahl, A.; Knuutila, H. K. Viscosity, 886 Density, and Volatility of Binary Mixtures of Imidazole, 2- 887 Methylimidazole, 2,4,5-Trimethylimidazole, and 1,2,4,5-Tetramethyli- 888 midazole with Water. J. Chem. Eng. Data 2019, 64, 507-516. 889

(44) Pinto, D. D. D.; Svendsen, H. F. An Excess Gibbs Free Energy 890 Based Model to Calculate Viscosity of Multicomponent Liquid 891 Mixtures. Int. J. Greenhouse Gas Control 2015, 42, 494-501. 892

(45) Pinto, D. D. D.; Monteiro, J. G. M.-S.; Johnsen, B.; Svendsen, H. 893 F.; Knuutila, H. Density Measurements and Modelling of Loaded and 894 Unloaded Aqueous Solutions of MDEA (N-Methyldiethanolamine), 895 DMEA (N,N-Dimethylethanolamine), DEEA (Diethylethanolamine) 896 and MAPA (N-Methyl-1,3-Diaminopropane). Int. J. Greenhouse Gas 897 Control 2014, 25, 173-185.

(46) Iloukhani, H.; Almasi, M. Densities and Excess Molar Volumes of 899 Binary and Ternary Mixtures Containing Acetonitrile + Acetophenone 900 + 1,2-Pentanediol: Experimental Data, Correlation and Prediction by 901 PFP Theory and ERAS Model. J. Solution Chem. 2011, 40, 284-298. 902

(47) Acevedo, I. L.; Pedrosa, G. C.; Katz, M. Excess Molar Volumes 903 and Excess Viscosities of N-Butylamine + 1,4-Dioxane + Carbon 904 Tetrachloride System at 298.15 K. Can. J. Chem. 1991, 69, 1006-1010. 905

(48) Cibulka, I. Estimation of Excess Volume and Density of Ternary 906 Liquid Mixtures of Non-Electrolytes from Binary Data. Collect. Czech. 907 Chem. Commun. 1982, 47, 1414-1419.

908

(49) Nagata, I.; Tamura, K. Excess Molar Enthalpies for the Methanol- 909 1-Butanol-Benzene System at 25. Degree. C. J. Chem. Eng. Data 1988, 910 33, 283-285.

(50) Redlich, O.; Kister, A. T. Algebraic Representation of 912 Thermodynamic Properties and the Classification of Solutions. Ind. 913 Eng. Chem. 1948, 40, 345-348.

914

(51) Singh, P. P.; Nigam, R. K.; Sharma, S. P.; Aggarwal, S. Molar 915 Excess Volumes of Ternary Mixtures of Nonelectrolytes. Fluid Phase 916 Equilib. 1984, 18, 333-344.

(52) Pinto, D. D. D.; Knuutila, H. K. Density Calculations of Aqueous 918 Amine Solutions Using an Excess Gibbs Based Model. Braz. J. Chem. 919 Eng. 2019.

(53) Arrhenius, S. Über Die Innere Reibung Verdünnter Wässeriger 921 Lösungen. Z. Phys. Chem. 1887, 1, 285-298.

(54) Grunberg, L.; Nissan, A. H. Mixture Law for Viscosity. Nature 923 1949, 164, 799-800. 924

(55) Song, Y.; Mathias, P. M.; Tremblay, D.; Chen, C.-C. Liquid 925 Viscosity Model for Polymer Solutions and Mixtures. Ind. Eng. Chem. 926 Res. 2003, 42, 2415-2422.

(56) Bingham, E. C.; Jackson, R. F. Standard Substances for the 928 Calibration of Viscometers. J. Wash. Acad. Sci. 1917, 7, 53-55. 929

(57) Spieweck, F.; Bettin, H. Review: Solid and Liquid Density 930 Determination/Übersicht: Bestimmung Der Dichte von Festkörpern 931 Und Flüssigkeiten. TM, Tech. Mess. 1992, 59, 285-292. 
933 (58) Yaws, C. L. Yaws' Critical Property Data for Chemical Engineers 934 and Chemists; Knovel: Norwich, NY, 2012.

935 (59) LAPWS R12-08: Viscosity of Ordinary Water. http://www.iapws. $936 \mathrm{org} /$ relguide/viscosity.html (accessed Jun 7, 2019).

937 (60) Qunfang, L.; Yu-Chun, H. Correlation of Viscosity of Binary 938 Liquid Mixtures. Fluid Phase Equilib. 1999, 154, 153-163.

939 (61) Hartono, A.; Svendsen, H. F. Density, Viscosity, and Excess 940 Properties of Aqueous Solution of Diethylenetriamine (DETA). J. 941 Chem. Thermodyn. 2009, 41, 973-979.

942 (62) Rafiee, H. R.; Ranjbar, S.; Poursalman, F. Densities and 943 Viscosities of Binary and Ternary Mixtures of Cyclohexanone, 1,4944 Dioxane and Isooctane from $\mathrm{T}=(288.15$ to 313.15$) \mathrm{K}$. J. Chem. 945 Thermodyn. 2012, 54, 266-271.

946 (63) Eimer, D. Gas Treating: Absorption Theory and Practice; John 947 Wiley \& Sons, Inc.: Chichester, West Sussex, 2014.

948 (64) Barzagli, F.; Lai, S.; Mani, F. Novel Non-Aqueous Amine 949 Solvents for Reversible $\mathrm{CO}_{2}$ Capture. Energy Procedia 2014, 63, 17959501804.

951 (65) Wang, X.; Kang, K.; Wang, W.; Tian, Y. Volumetric Properties of 952 Binary Mixtures of 3-(Methylamino)Propylamine with Water, N953 Methyldiethanolamine, N,N-Dimethylethanolamine, and N,N-Dieth954 ylethanolamine from (283.15 to 363.15) K. J. Chem. Eng. Data 2013, $95558,3430-3439$.

956 (66) Maham, Y.; Teng, T. T.; Hepler, L. G.; Mather, A. E. Densities, 957 Excess Molar Volumes, and Partial Molar Volumes for Binary Mixtures 958 of Water with Monoethanolamine, Diethanolamine, and Triethanol959 amine from 25 to $80^{\circ}$ C. J. Solution Chem. 1994, 23, 195-205.

960 (67) Sathyanarayana, B.; Ranjithkumar, B.; Savitha Jyostna, T.; 961 Satyanarayana, N. Densities and Viscosities of Binary Liquid Mixtures 962 of N-Methylacetamide with Some Chloroethanes and Chloroethenes at $963 \mathrm{~T}=308.15 \mathrm{~K}$. J. Chem. Thermodyn. 2007, 39, 16-21. 